\title{
The canine in the dento-alveolar system
}

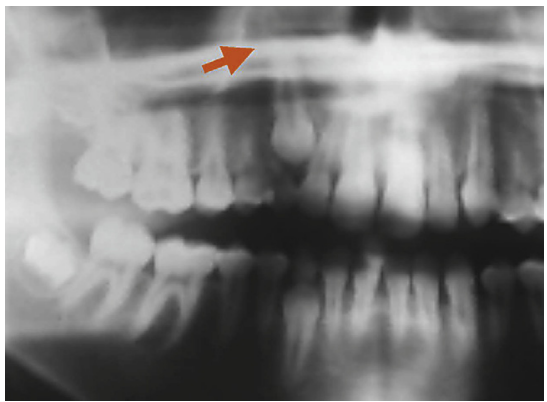

\section{Roland BENOÎT, Jean GRANAT}

\section{ABSTRACT}

In this paper we examine the placement of the human canine tooth in the dento-alveolar system in order to explain its phylogenesis and ontogenesis over the course of its interactions with other tissues. We explain the known genetic mechanisms that occur throughout its morphogenesis and during its eruption until the tooth takes its place in the oral cavity. We carefully examine the role that genetic and environmental factors play in causing anomalies in its form, maturation, eruption and function.

We show how environmental factors determine how well it becomes integrated into the already established dental functional schema.

\section{KEYWORDS}

Canine

Dento-alveolar system

Genetics

Interactions

Integration. 


\section{1 - INTRODUCTION}

Today, in the special field of embryonic, foetal and infant vertebral and craniofacial development, one would look in vain in a search for a perfect coordination between morphological, genetic, immunological, endocrine, environmental, orthopaedic, orthodontic and mechanical factors. That is why we shall examine each part of this complex separately, to see how they are all integrated into a new way that is based upon the Systems Biology concept that Zieglgansberger and Tolle introduced in $1993^{8}$ (fig. 1).

Following Systems Biology principles, we cannot study the canine tooth in isolation, because it is part of a system, the dentoalveolar system (fig. 2) During its ontogenesis we must examine it as it interacts with its alveolar tissue environment and becomes integrated into the functioning of the global system of which it is a part?

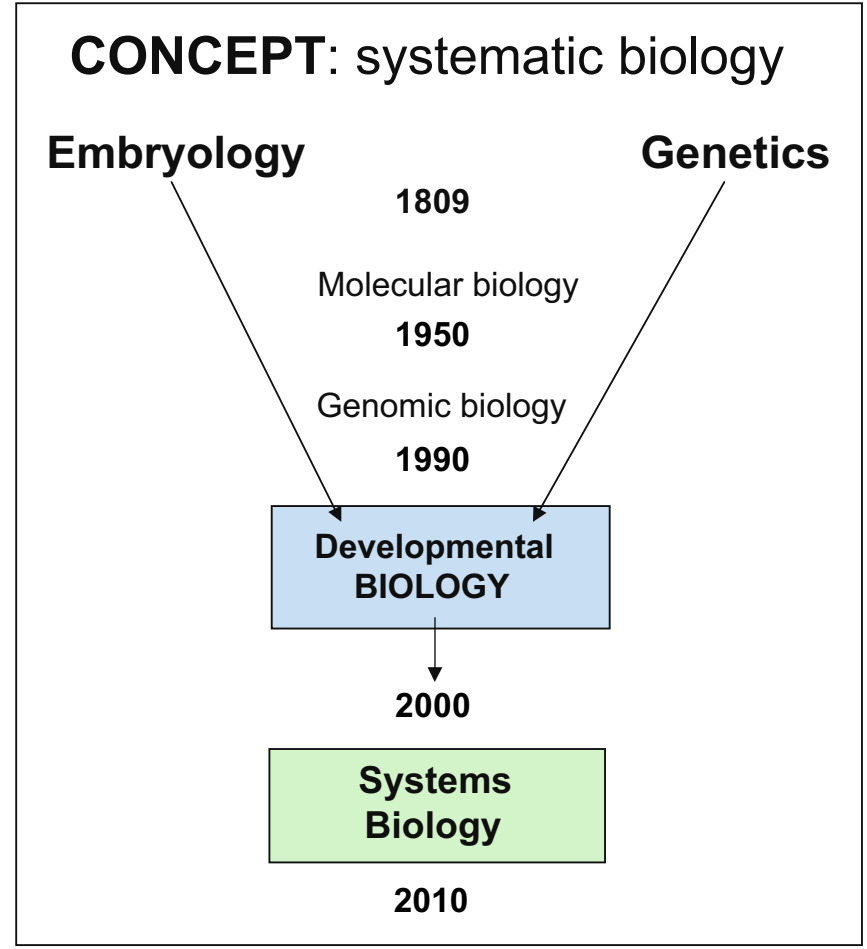

Figure 1

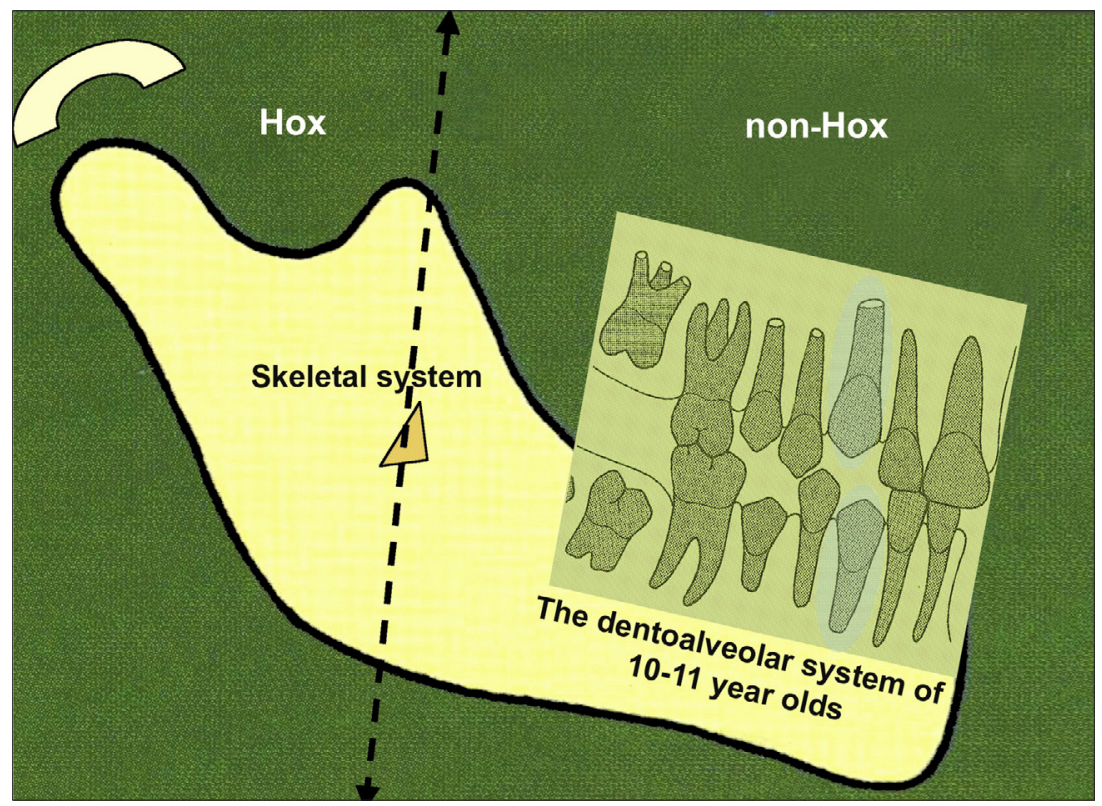

Figure 2

Systems biology or systematic biology. 


\section{2 - PHYLOGENESIS}

Palaeontologists have determined that the Homo genus emerged about 4 million years ago with Homo habilis, the common parent ancestor we share with two other daughter species that were our contemporaries for millions of years. Homo erectus disappeared some 200,000 years ago and the Neanderthals died out about 30,000 years ago, leaving us, the Homo sapiens as the only survivors.

The dental system of modern Man is, accordingly, the product of a long evolution. The three types of teeth, incisors, canines, and grinding premolars and molars, that comprise it first made their appearance in the early mammals. This longevity makes it clear that our conformation of teeth bestows an adaptive advantage that has been retained by Historic and modern mammals including man.

In the Homo genus, the canine is incisiform and does not protrude beyond the level of its neighbouring teeth. It has never developed into a pointed tooth so the human dental arch does not have the diastemas require to lodge their large pointed canines when upper and lower teeth occlude. Homo habilis had elliptically shaped dentoalveolar arches and the arches of Homo erectus had an extended elliptical shape.

In Homo neanderthalensis, the ellipse was flattened in its anterior segment. In Homo sapiens, the ellipse varies considerably within populations

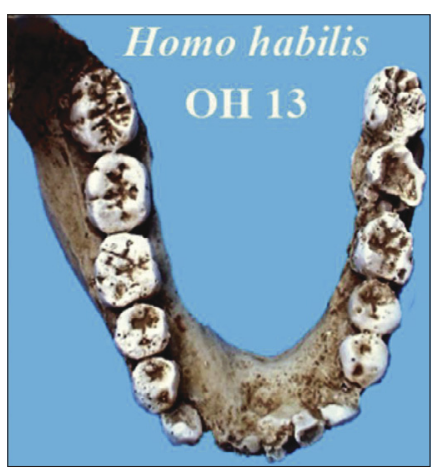

a

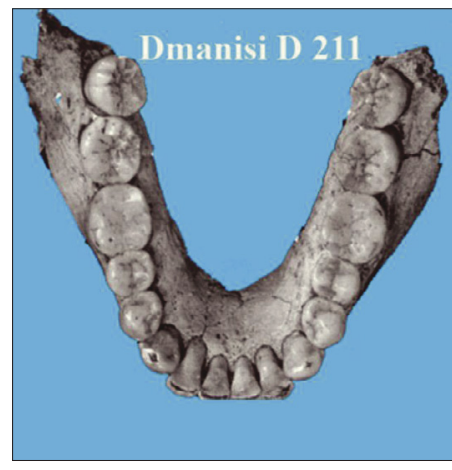

b

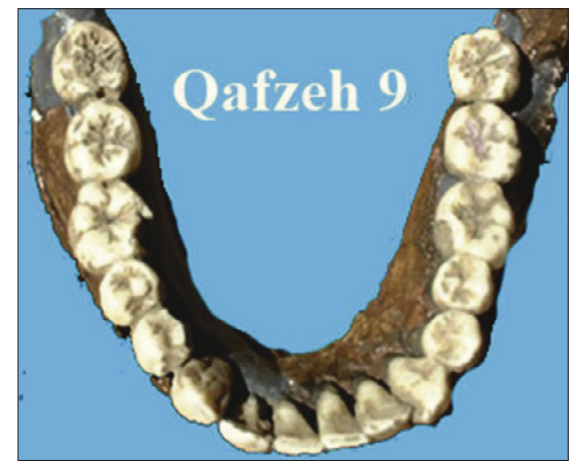

C
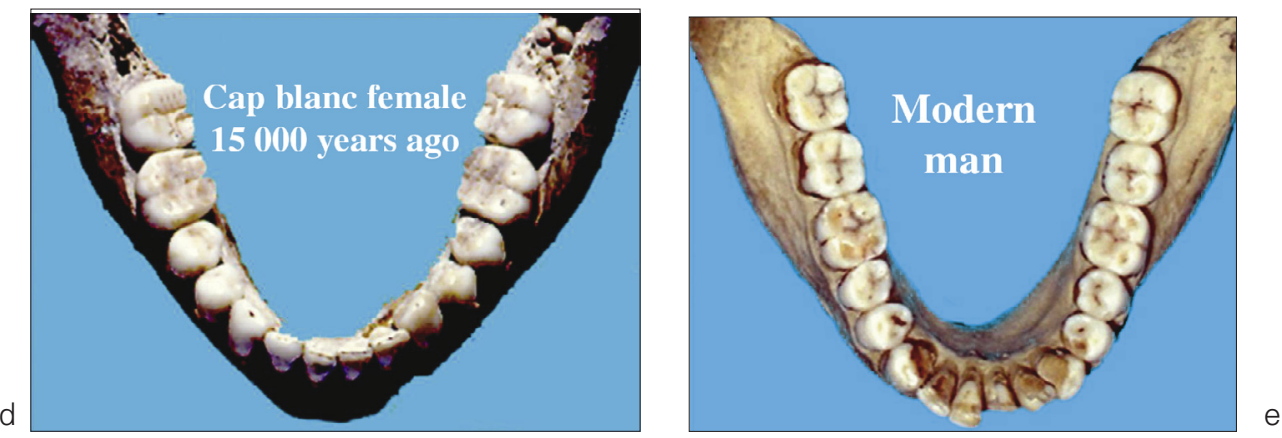

Figure 3 a to e

Shapes of dental arch from Homo habilis to the present. 


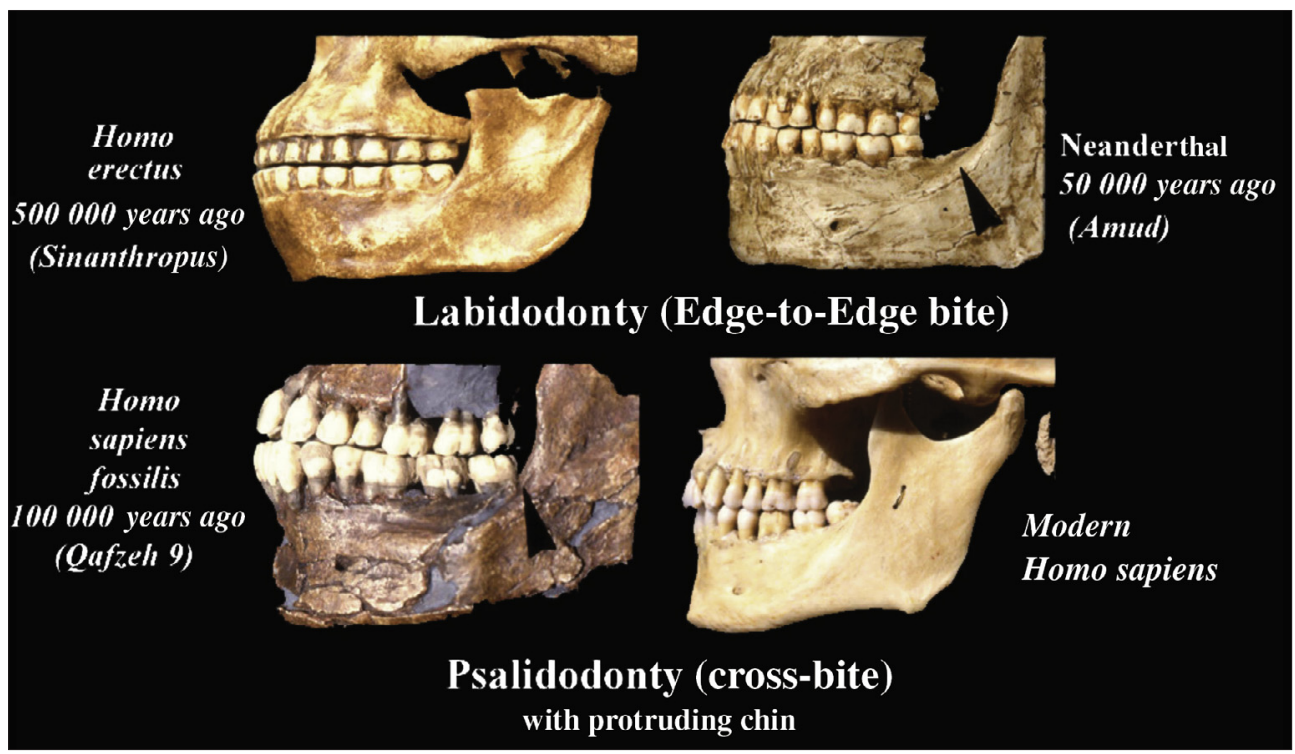

Figure 4

Types of occlusion.
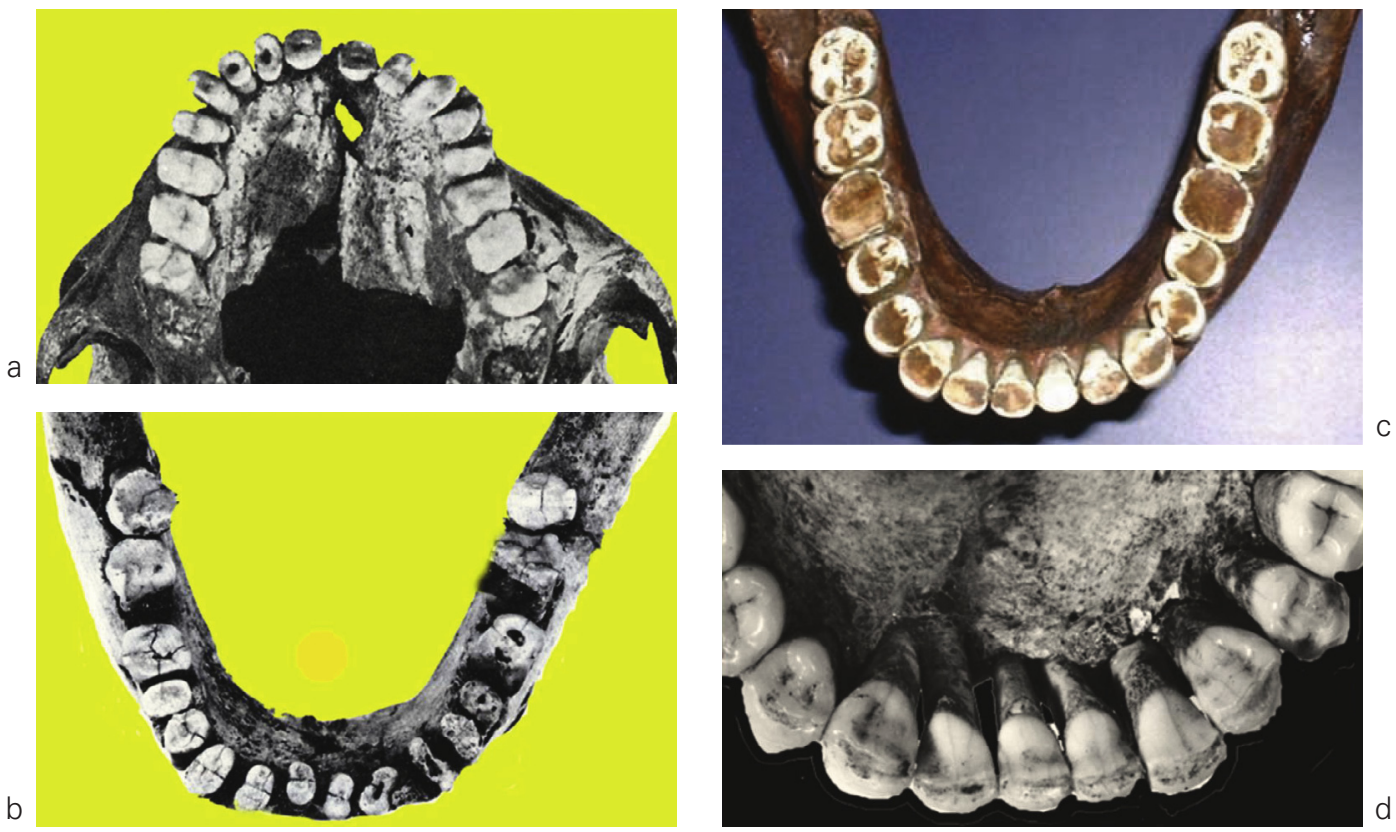

Figure 5 a to $d$

Neanderthals.

Canines of the same shape but differently abraded.

$a$ and $b$ : Neanderthal from La Ferrassie;

c: Tabun; D: Regourdou. 
and this masks the great inter-population variability (fig. 3 a to e) $)^{13}$.

In our evolutionary review we encounter Neanderthal fossils with highly abraded teeth and others in whose teeth the original indentations and fissures were still present. The same variation occurs in Homo sapiens where the canines represent a border zone between incisors and molars.

The anterior teeth of Neanderthals occluded in labidodontia, an edge to edge bite. As a result, with increasing wear, the canines are levelled, which confirmed the evolutionary tendency to keep them from playing a guiding role in masticatory and occlusal movements (fig. 5 a to $d$ ).

On the other hand, in the phylum which leads to modern man, Homo habilis to Homo sapiens, there has been less wear on the free incisal edge and the canine has a conical tip. The anterior teeth of Homo sapiens tend to exhibit Psalidodontia, or cross bite occlusion (fig. 4), which seems to be the result of a withdrawal of the dentoalveolar arch on the mandibular base. "In our opinion this emphasises chin protrusion"12.
Assumed age in years (in 6 month graduations)

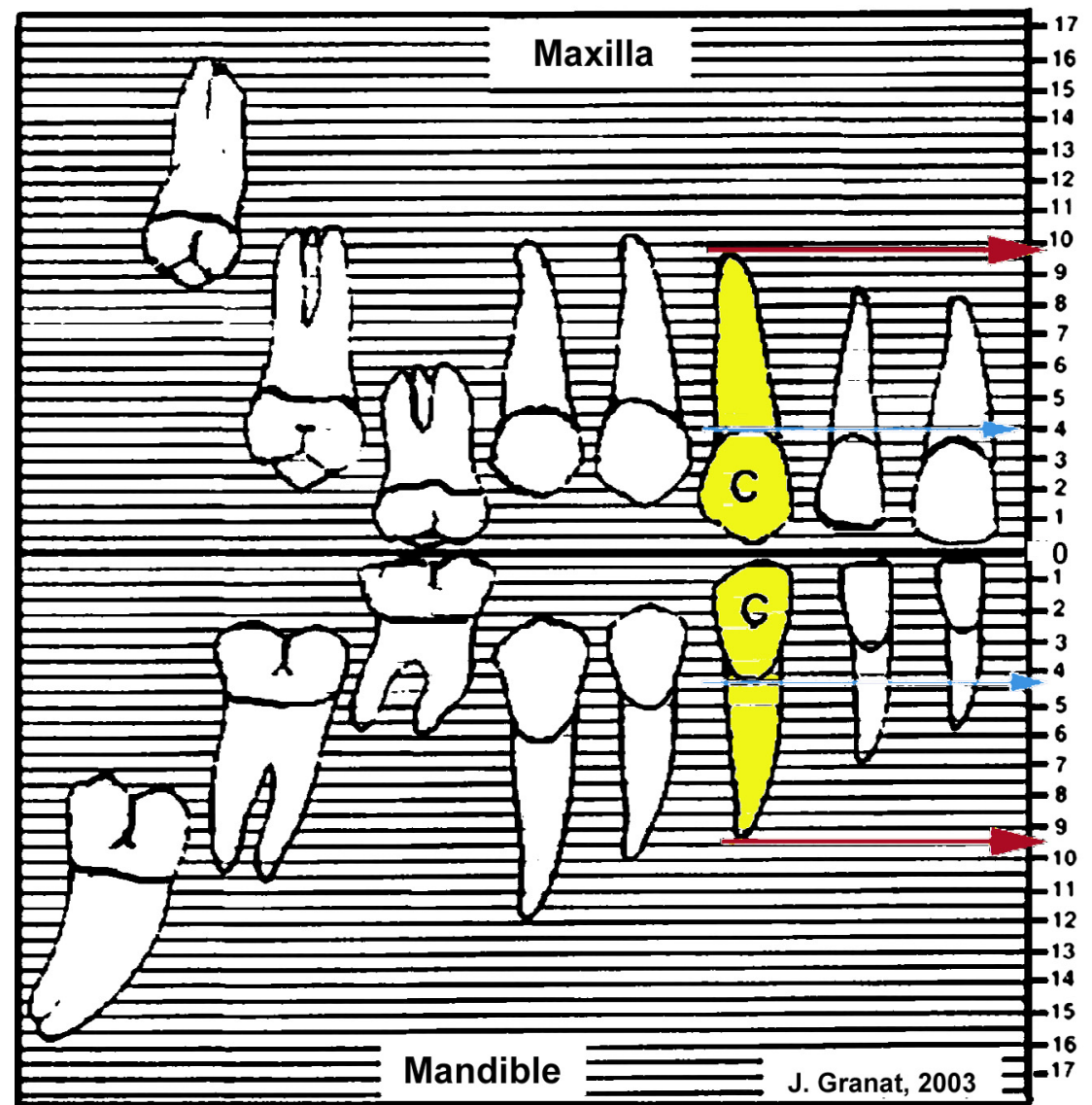

Figure 6

Chronology of maturation of permanent teeth in Neanderthals.
This table shows when the crowns and roots of the maxillary and mandibular canines begin to form. The age after birth is noted at the right.

In Neanderthals:

- the crown began to form at 6 months and was completed at 4 years (blue arrows);

- the root was completed at the age of 10 (red arrows).

We cannot estimate the ages of eruption of teeth into the buccal cavity in fossils because soft mucosal tissue is no longer present.

Note the early dental maturity of Neanderthals. The root of the canine completed its apexification at the age of 10 whereas in modern children, the canine is only starting its insertion in the arch at that age. Neanderthal children had to learn to eat on their own at an early age. Childhood was short. (Need for survival and environmental adaptation). 
This type of occlusion is favourable because it slows the erosion of teeth thus conserving the ancestral tribosphenic molars more effectively. It is important to remember in considering the abrasion of teeth over time that the life span of pre-historic humans was far shorter than it is today.

These inter-arch relationships help preserve vertical dimension, enabling the incisors to cut food and other material, and also improve elocution. The canine remains pointed and plays its role as anterior occlusal guide, this time with the incisors.

The dental system in Homo has undergone various adaptations in response to individual lifestyles and variations in environment. Neanderthal canines, for example, were strong, reaching some of the largest dimensions noted in hominids, particularly in their labiolingual surfaces, while the length of the roots was unchanged (fig. 5 a to d). Palaeo-odontological studies have revealed some differences in morphology and dental maturation between species in the Homo genus. Thus, in Neanderthals, we note a general tendency to early dental maturity and a different order of eruption: the permanent canines come into the arch before the first premolars do (fig. 6) ${ }^{11}$.

In the Homo genus, the dental system has been relatively stable, maintaining the three classes of teeth as well as the maturation and eruption chronologies, thus leaving a trail of genetic information as it develops. The differences noted in maturation seem to be linked to lifestyle, nutrition and environment. Nutritional modifications have probably induced different methods of mastication.

\section{3 - GENETIC MECHANISMS OF DEVELOPMENT OF THE CANINE}

In this very long history of teeth the cynodonts of some 250 million years ago, unlike other reptiles of that era, had teeth that were grouped into three different classes in each half-jaw. This characteristic must have been very favourable because it has continued to the present day in modern man. The first placental mammals, which appeared some 110 million years ago, started to specialise these classes. In the canine class, there was only one tooth, the canine itself. Its size varied from species to species, but in general the canine preserved its crown morphology displaying a highly developed median coronal-medial mamelon, conoid with a pointed tip. It is convex on all of its surfaces including those of its root, which is single, strong, long, the longest of all the teeth in the species. The genetics of craniofacial development provide better understanding of odontogenesis in humans as well as of the long evolutionary development of prehistoric humans. Six million years ago the teeth of the first Hominids, like the Orrorin,24,30, had already undergone a long period of evolutionary change. They were the fruit of a series of mutations that had affected the interactions of an existing model. But in hominids, since the beginning, these mutations have allowed the canine to preserve its relatively stable shape, which has been bequeathed to modern humans.

In 1875, Charles Darwin reported that some men, who had relatively little hair on their heads, suffered immensely 
from the heat because their skin was dry $^{3}$. These men also displayed anomalies in their teeth and sweat glands.

Darwin had made a connection between these different ectodermal features.

During the second half of the $20^{\text {th }}$ century, new analytical techniques, teratogenesis, cultures, tissue grafts, and breeding of transgenic mice, have elucidated the role of certain mechanisms in the buds of developing teeth. For example, since the end of the 20th century, genetics and molecular biology have determined how genes and proteins ${ }^{16}$ participate in the development of teeth, glands, hair, integuments and scales (fig. 7). Thus, the gene EDA* and its
$E D A R^{*}$ * receptor, first uncovered in mice, is responsible for hypohydrotic ectodermal dysplasia) ${ }^{17}$, the dry skin syndrome Darwin had noted. The EDA gene expresses itself in linkage with other molecules in the TNF (tumour necrosis factor) family, during interactions controlled by many transcription and signalling factors for different follicles, including the dental germs $2,3,1,21,33$.

\section{3 - 1 - Ontogenesis canine genetics}

\section{- Origin}

Odontogenetic cells originate in the neural crests of the neural tube, beginning on day 17 in a human embryo (fig. 8).

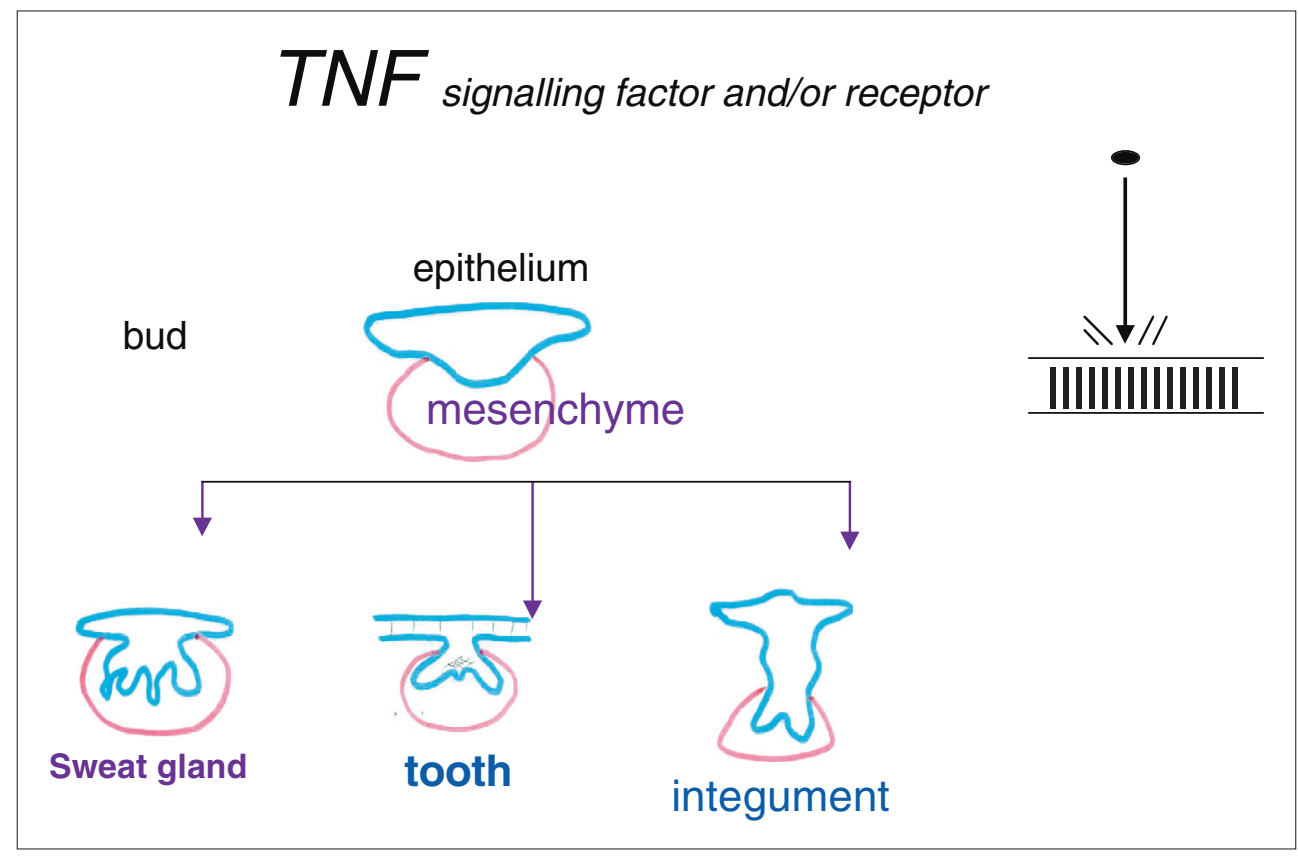

Figure 7

Anhydrotic ectodermal dysplasia.

*EDA: anhydrotic ectodysplasia

**EDAR: anhydrotic ectodysplasia receptor 


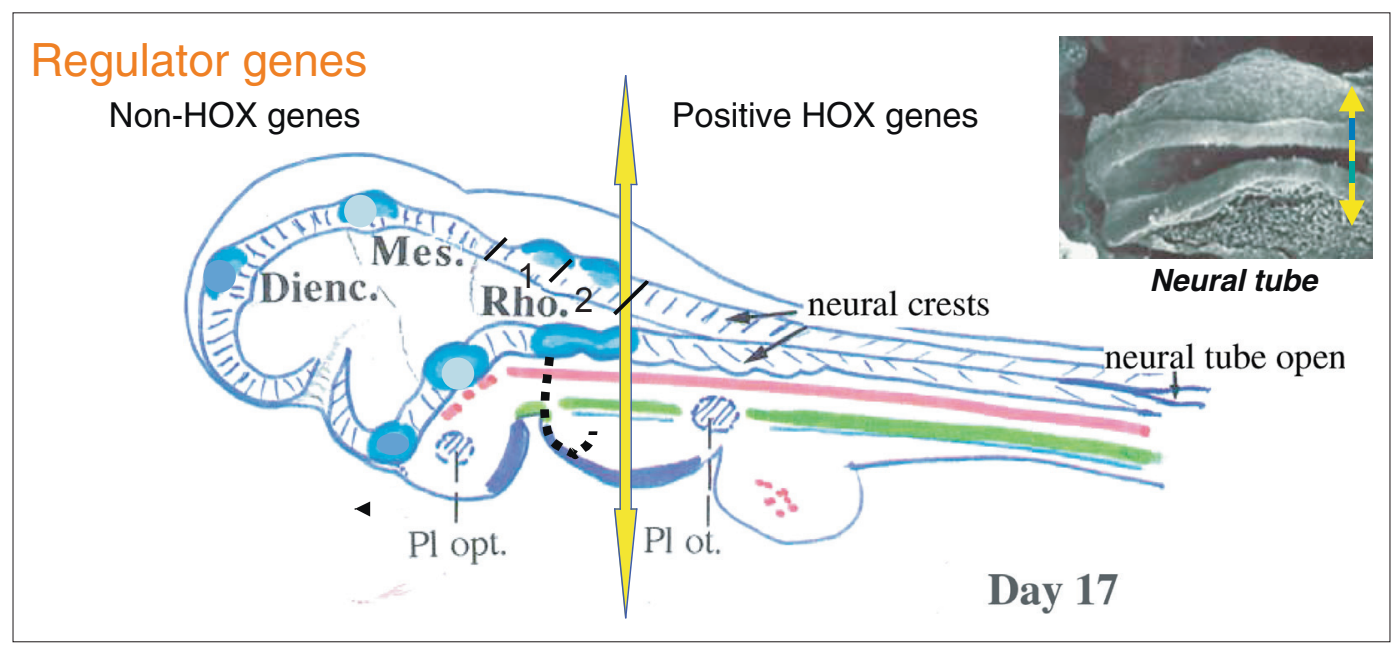

Figure 8

Origin of neural crest cells for odontogenic development.

Following the anteroposterior axis genetically determined by the HOX genes as far as the rhombomere: Rho2 and anterior to this limit, the neural crest cells form diencephalic, mesencephalic and rhomboencephalic cell clusters for odontogenic development 4 .

\section{3 - 2 - Migration and localisation}

The migration of neural crest cells from the diencephalic cluster towards the nasofrontal bud for the incisors starts at three weeks. The mesencephalic cluster supplies the cells which migrate into the anterior part of the maxillary bud and mandibular arch, initiating development of the canines. Finally, cells from the rhomboencephalic cluster disperse themselves in the posterior parts of the maxillary and mandibular buds.
These migrations take place on each side of the neural tube, passing through the facial mesenchyme under the control of a great many genes: PAX, OTX, Gsc, MSXs, DLS associated with many signalling factors (fig. 9 a).

These cell populations form the skeletogenic and odontogenic ectomesenchyme. This is found under the buccal epithelium in three cell classes: incisor, canine and molar, for each hemi-arch (fig. 9 b), governed by the PAX gene.

On the basis of experimental work in mice and/or cell cultures, Thomas and Sharpe 32 have suggested that a dental "homeobox code" controls these pooled localisations. The homeobox code also postulates that, within a dental morphogenetic class, a specific combination dictates the position and morphology that the tooth buds, including those of canine teeth, must take (fig. 10, 11). The many experimental results 


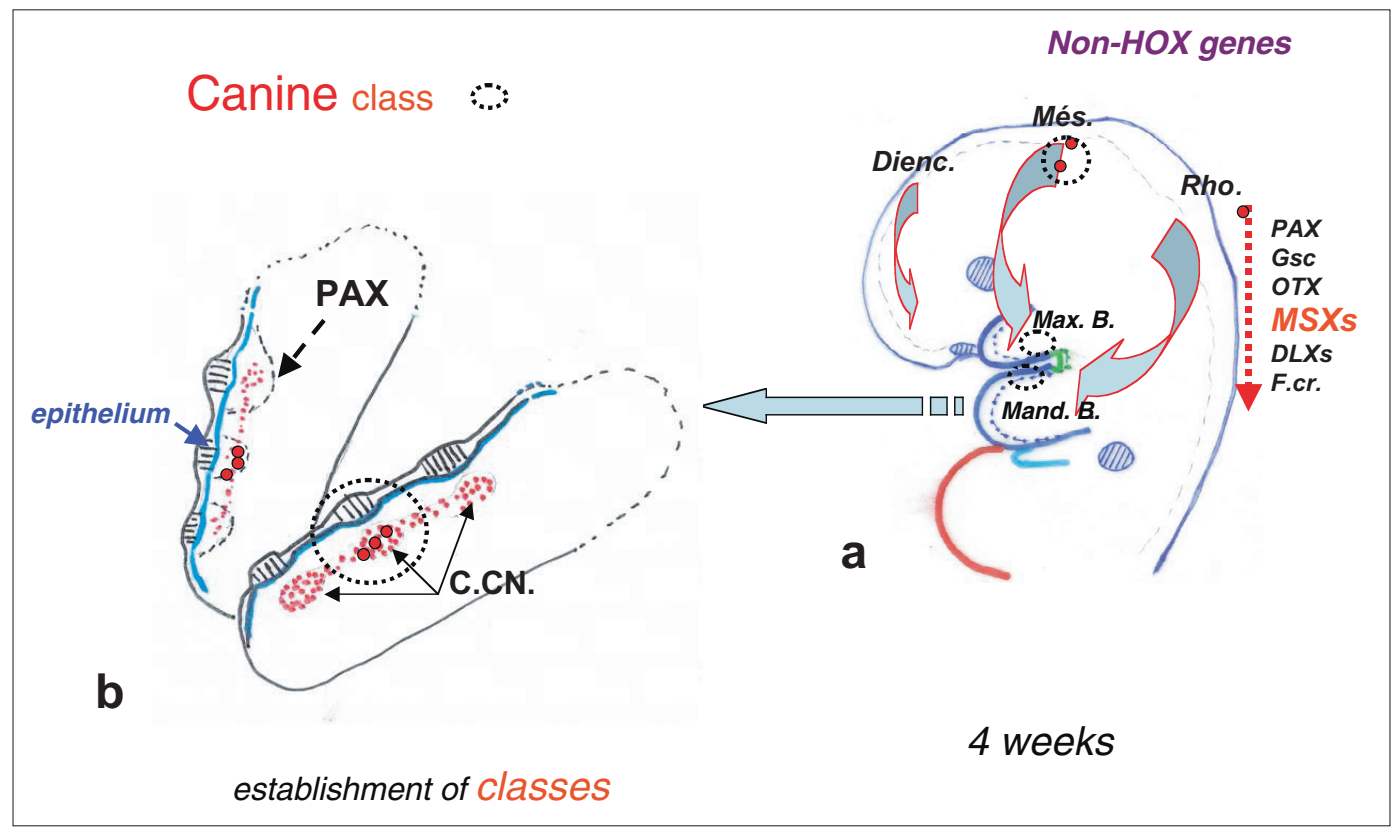

Figures $9 a$ and $b$

a: Migration

b: Localisation of neural crest cells at 4 weeks.

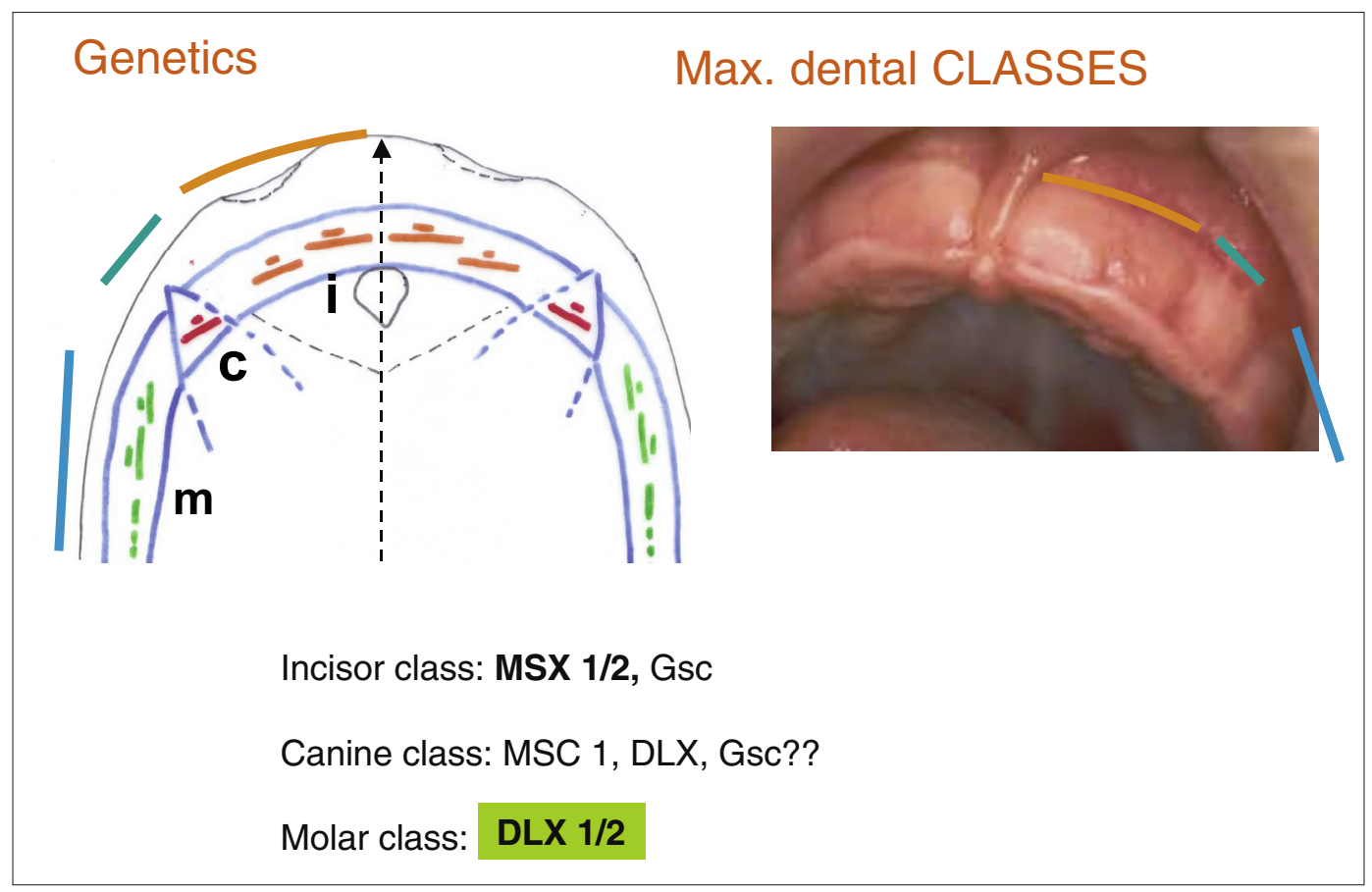

Figure 10

Dental maxillary "homeobox code". 
of tissue recombinations show that the buccal epithelium has the property of containing the necessary signals for odontogenesis. But the fact that the maxillary and mandibular epithelia are interchangeable as ectomesenchyme initiators is a good indication that the specificity of the response to epithelial initiation is the intrinsic property of ectomesenchymatous cells. Therefore

\section{Genetics}

Incisor class: MSX 1/2, Gsc

Canine class: MSC 1, DLX, Gsc?

Molar class: DLX 5/6
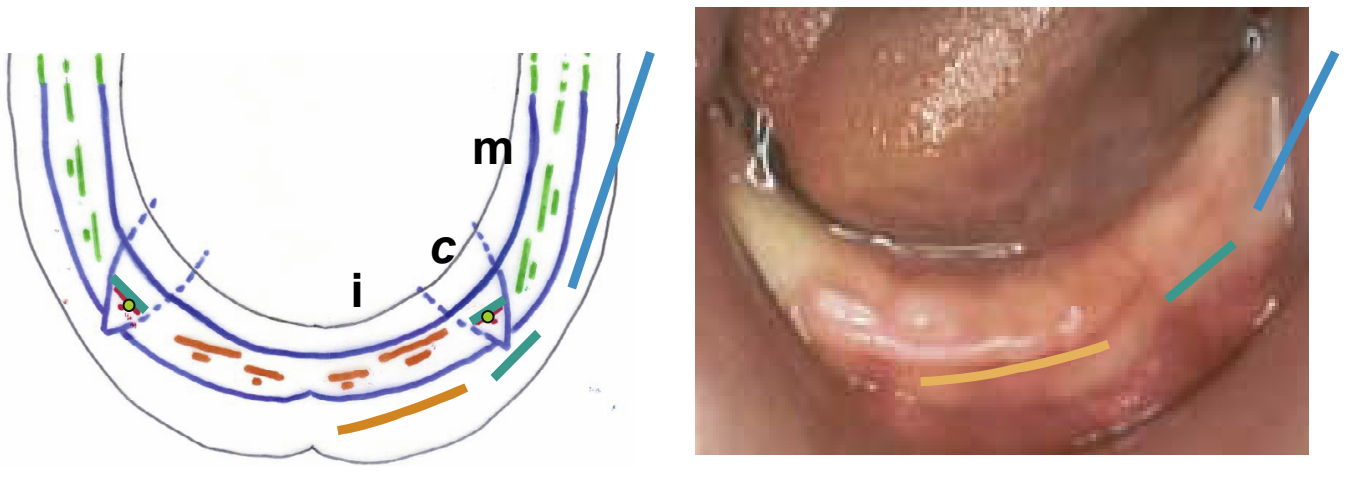

Figure 11

Dental mandibular "homeobox code".

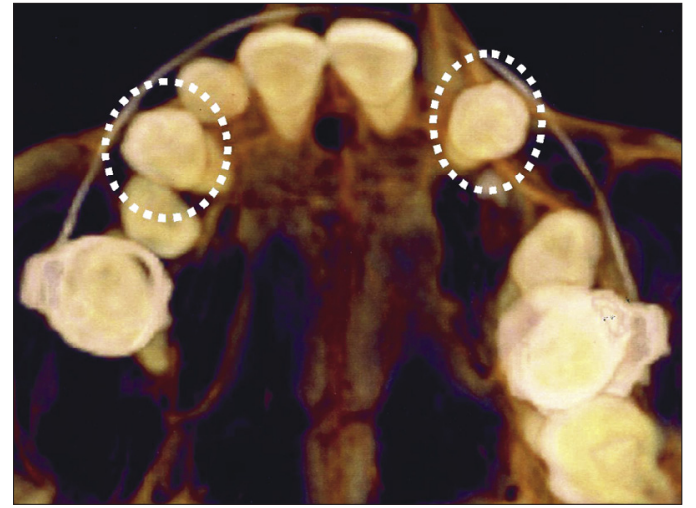

a

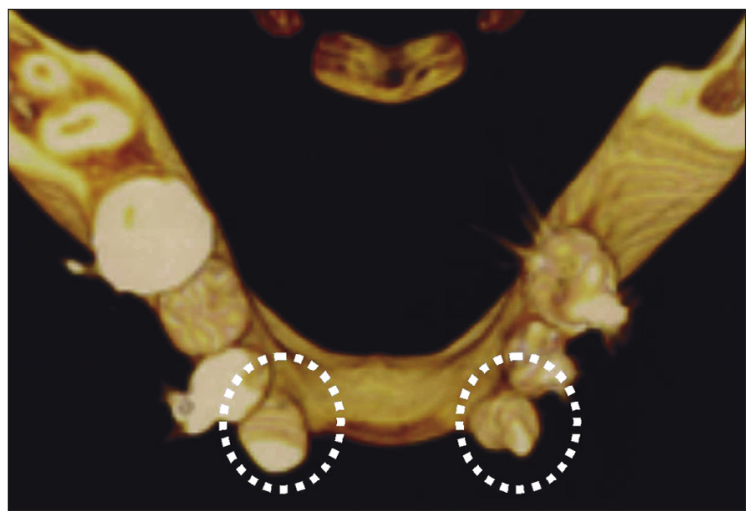

b

Figures 12 and $b$

Canines present in a case of maxillary and mandibular oligodontia. 
maxillary epithelium in the molar class associated with mandibular ectomesenchyme is the origin of differentiation into mandibular molars.

Clinically speaking, in cases of agenesis or oligodontia, the missing teeth in the maxilla and mandible underscore the specificity of the three classes, incisor, canine and molar. In these situations, the canine class alone is not affected, emphasising the particularity and permanence of the canine class in humans (fig. $12 \mathrm{a}$ and b).

NB: the description of this development deals with the temporary canine which will be replaced by its permanent successor: the adult canine tooth then develops in the same way.

\section{3 - 3 - Interactions}

In human embryos, at 6 weeks the first interaction signal comes from the epithelium at a precise spot (canine class) relative to the cellular pool of ectomesenchyme. At this stage, the signalling factor, Shh, BMP4, FGF8, ligand Eda, and its receptor Edar are expressed in the epithelium. They interact with the transcription factor PAX, DLX, (fig. 13 a and b).

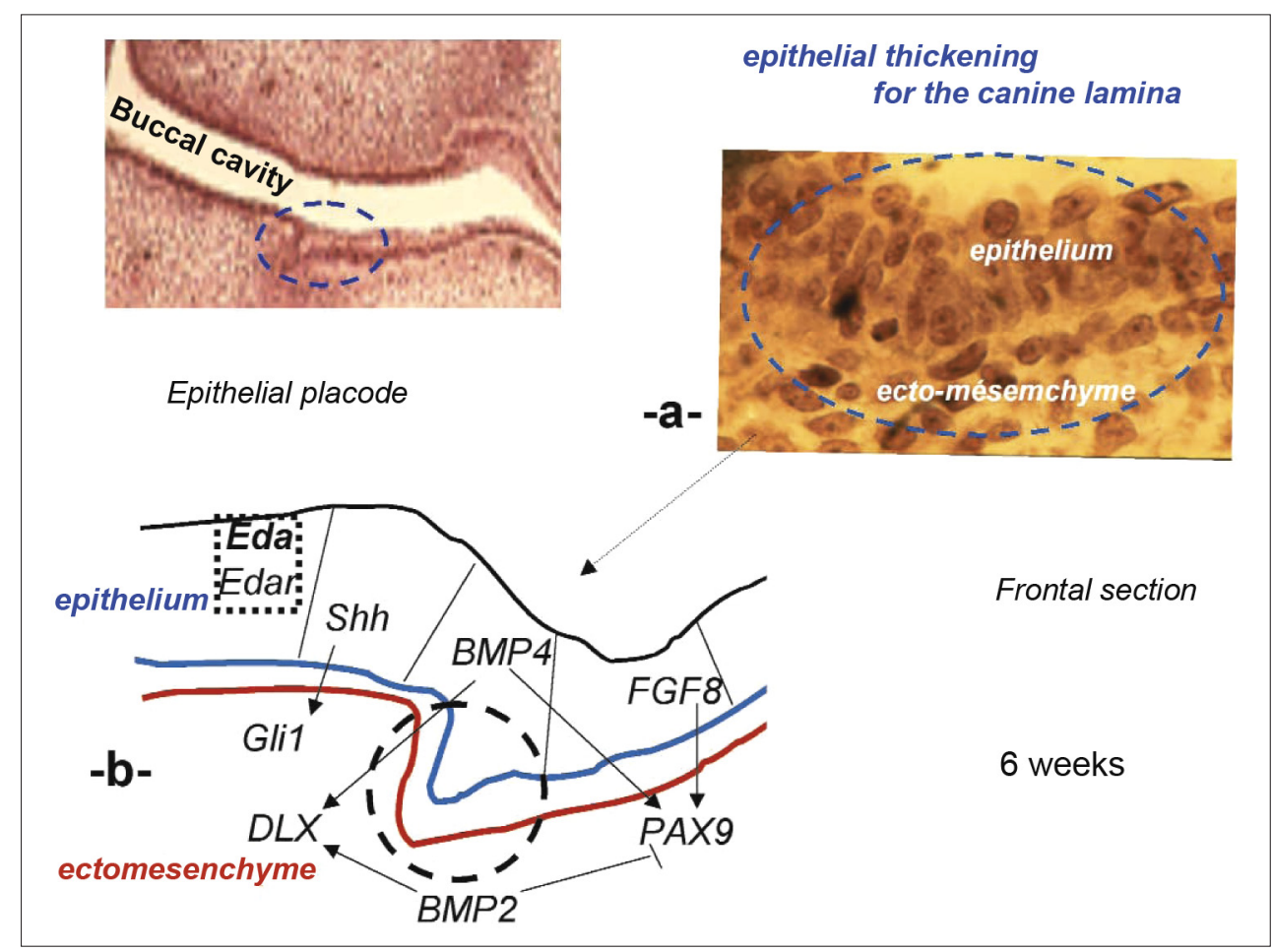

Figures $13 a$ and $b$

Interactions. 


\section{3 - 4 - Crown morphogenesis}

During the ninth week, crown morphogenesis of the canine continues. The epithelial signalling centre, the enamel knot, orchestrates modelling of the crown's shape (fig. 14 a). This knot of primary enamel develops in the centre of the internal epithelium. The cells composing it multiply over a short time to form the epithelial diaphragms surrounding the odontogenic mesenchyme, the future pulp. This cell multiplication continues under the expression of signalling and transcription factors BMPs, Wnt, Shh, Eda, MSX2, Lef1 and P21 in the enamel knot26 (fig. 14 b).
These cells are rapidly condemned to cell death (apoptosis) in the enamel knot. This primary knot is thought to be only a provisional centre of activity which regulates cell multiplication and death to give shape to the crown. After the primary knot has disappeared the interface between the epithelium and mesenchyme grows larger and begins to establish the base of the crown.

At the bell stage, the enamel organ may thicken on the lingual surface, giving rise to the more or less marked cingulum (fig. $14 \mathrm{c}$ ).

The role of the concentration of the ligand EDA at the epithelial thickening stage and the gingivolabial wall seems to be limited

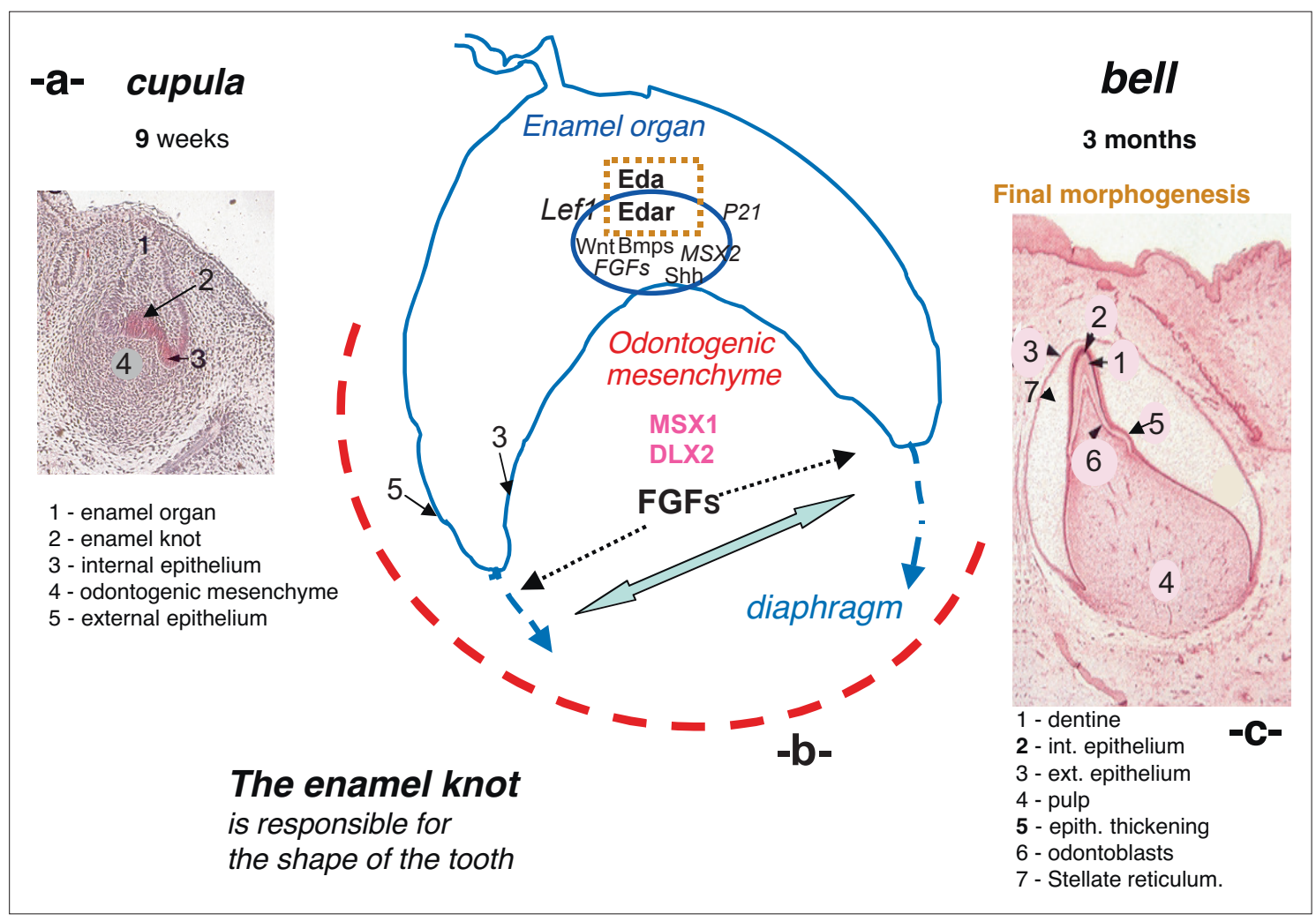

Figure 14 a to $c$

Stages in crown morphogenesis. 
to determining the dimension and position of the canine class. The relationship between the ligand EDA and receptor EDAR at the bell stage helps to install the cuspid in its central position. If too much EDAR is produced, more than the amount of ligand EDA, a dwarf, ectopic canine tooth may be the result.

Meanwhile, in the dental pulp, MSX1, DLX2 continue to be expressed.

\section{3 - 5 - Root morphogenesis}

After complete formation of the crown, on the lateral edges of the enamel organ, the external and internal epithelia form a double leaf: Hertwig's epithelial root sheath, which proliferates towards the apex indicating the future shape of the root, a process exclusive to the canine. During root development, Hertwig's root sheath limits the dental papilla except at its base, to constitute the epithelial diaphragm surrounding the apical foramen (fig. 15). The part of the dental follicle which is in contact with the root, gives rise to cementum, the periorodontal ligament and probably alveolar bone.

NB: the internal epithelium interacts with the mesenchyme for differentiation of the odontoblasts destined to form the dentine.

The epithelium is fragmented and leaves the dentine in contact with the follicular sac mesenchyme. The cementoblasts then differentiate and the acellular cementum is formed.

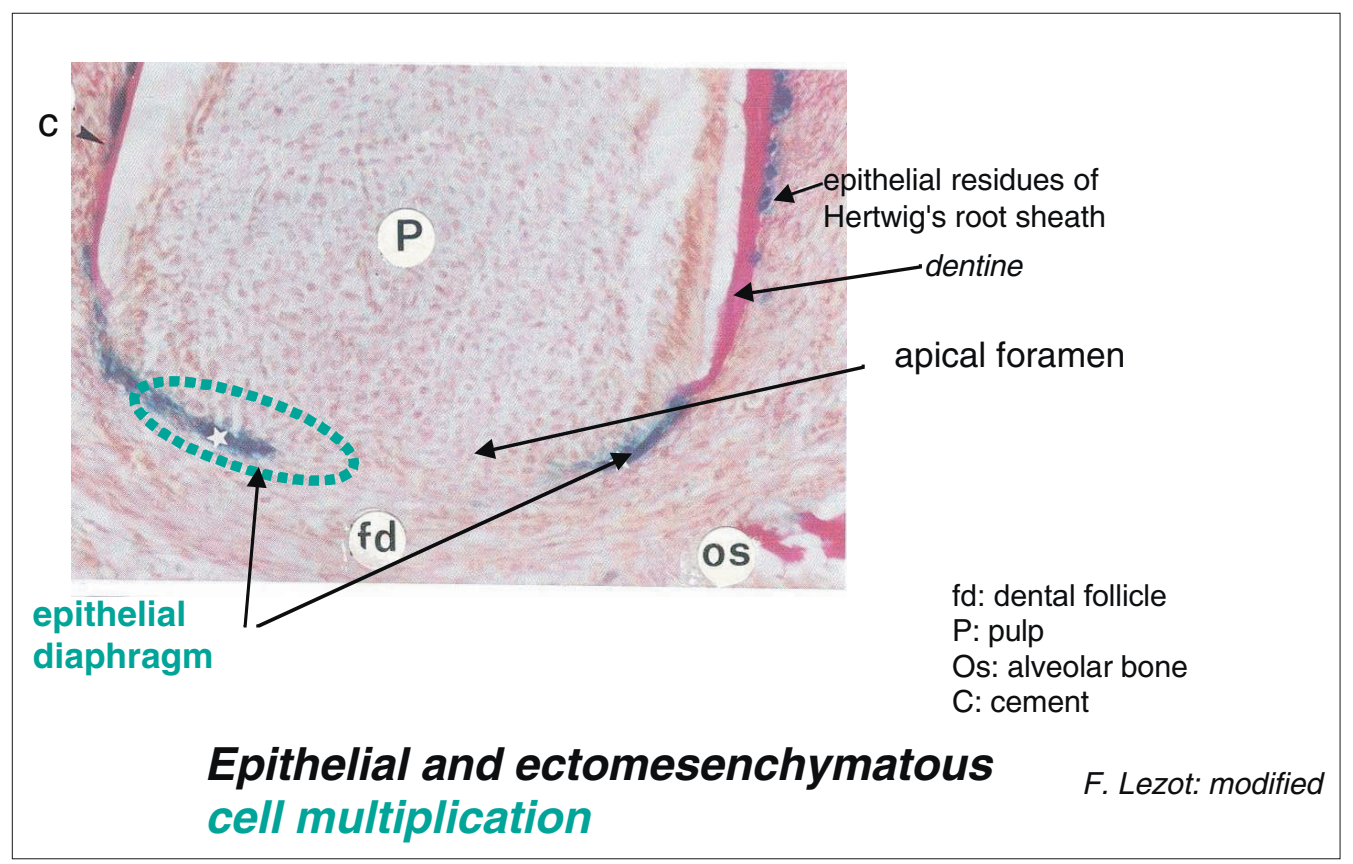

Figure 15

Terminal root morphogenesis. 


\section{3 - 6 - Genetic mechanisms}

Root morphogenesis takes place under the stimulus of genetic interactions in 3 sites:

- Hertwig's root sheath

- pulp

- the follicular sac.

We do not yet have a view of the nature of the morphogenesis of roots as precise as that of crowns. Some developmental biology studies on transgenic mice have shown that homeobox genes are involved in root construction. These studies confirm the role of MSX1 and MSX2 during the early stages. Thus, in MSX2-/- mice, imperfect amelogenesis and dentinogenesis, root dysmorphism and osteoporosis are noted 9 .
The follicular sac around the dental germ is also a tissue of ectomesenchymatous origin composed of different cell populations from neural crest cells. Some of these cells develop into cementoblasts, some into periodontal ligament fibroblasts and some into alveolar bone osteoblasts. The BMPs produced by Hertwig's root sheath, or found in the enamel matrix seem to play a part in the various dental follicle cell populations. But some mechanisms of action are not yet known.

After birth, if MSX1 is strongly expressed in the basal bone, MSX2 is the most active during the growth of alveolar bone ${ }^{5}$. Expression of these two genes is activated by growth factor BMPs. In return, MSX1 and MSX2 stimulate the expression of these growth factors (fig. 16).

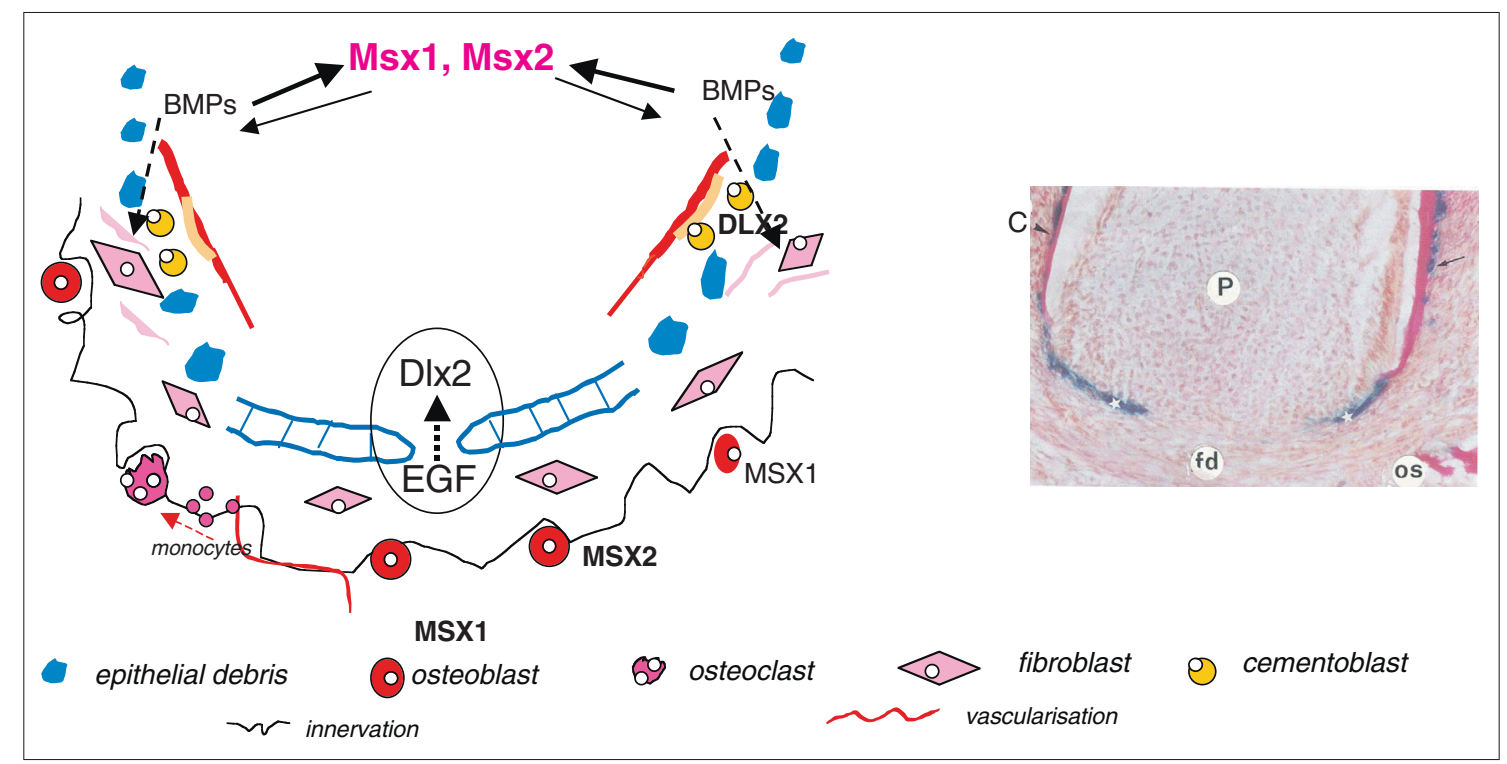

Figure 16

Root morphogenesis and eruption (mechanisms). Interactions in the dentoalveolar system and cell differentiation. 


\section{4 - ERUPTION}

At present, eruption is considered to be a multifactorial process ${ }^{18}, 31$. Studies and experiments performed on the continuous tooth eruption that occurs in species like mice show that it requires force derived from the pulp and the surrounding connective tissues of the dental follicle and/or the periodontal ligament. Eruption starts from the beginning of root morphogenesis in an axial direction, so that the eruptive phase is oriented in that direction. This force, which is maximal during the emergence of the crown in the oral cavity, is around $50 \mathrm{mg}$ for the permanent canine which emerges one $\mathrm{mm}$ per month. The action of the eruptive forces operating against an opposing force an eruption rhythm. For the permanent canine, this resistance may come from the subjacent connective tissue, countering epithelial tissue apoptosis in the gubernacular canal, or the alveolar bone as the axis of the tooth changes 6 .

\section{4 - 1 - Eruption mechanisms (permanent canine)}

Like root morphogenesis, eruption continues during a phase of allometric growth under the action of genetic interaction in the three elements of the dentoalveolar system: follicle sac, Hertwig's root sheath, and pulp.

But all the mechanisms of tooth eruption are not yet known. During the eruptive phases of animals with continuous tooth eruption, like mice, DLX2 is strongly expressed in the pulp in association with a growth factor, EGF, and epithelial ameloblastin close to the diaphragm. Reorganization of the alveolar bone beyond the apex as well as reorganization of the alveolar bone which crosses the tooth are both required to support eruption. At this stage, the enamel organ and/or Hertwig's root sheath participate in response to parathyroid hormone and interleukin $1 \alpha$ stimulus. EGF and TGF $\beta 1$ then join the action to recruit monocytic lines. This is how dental follicle monocytes develop macrophages and osteoclasts. The signalling factor MCSF (macrophage colony-stimulating factor) and increasing activity of the RANK receptor determine the differentiation of multinucleated osteoclasts. The formation of osteoclasts inhibits the synthesis of osteoprotegerin (OPG) by osteoblasts for a time 6 .

It is clear that this reorganizatio of the alveolar bone requires interaction between osteoclasts and osteoblasts ${ }^{1}$, which brings the transcription factor Cbfa1 (Runx2) into the constructive phase, regulating eruption (fig. 17) 14 .

A permanent canine which is in a lingual or a palatal position cannot erupt until the root of the temporary tooth, which is inside the same bony crypt, begins to resorb. This crypt is not completely closed because it opens into the gubernacular canal, which has a terminus in the buccal mucosa (fig. 18).

During the initial phases of eruption of the permanent canine, the bone separating it from the temporary tooth is resorbed so that the multinucleated odontoclasts can resorb the 


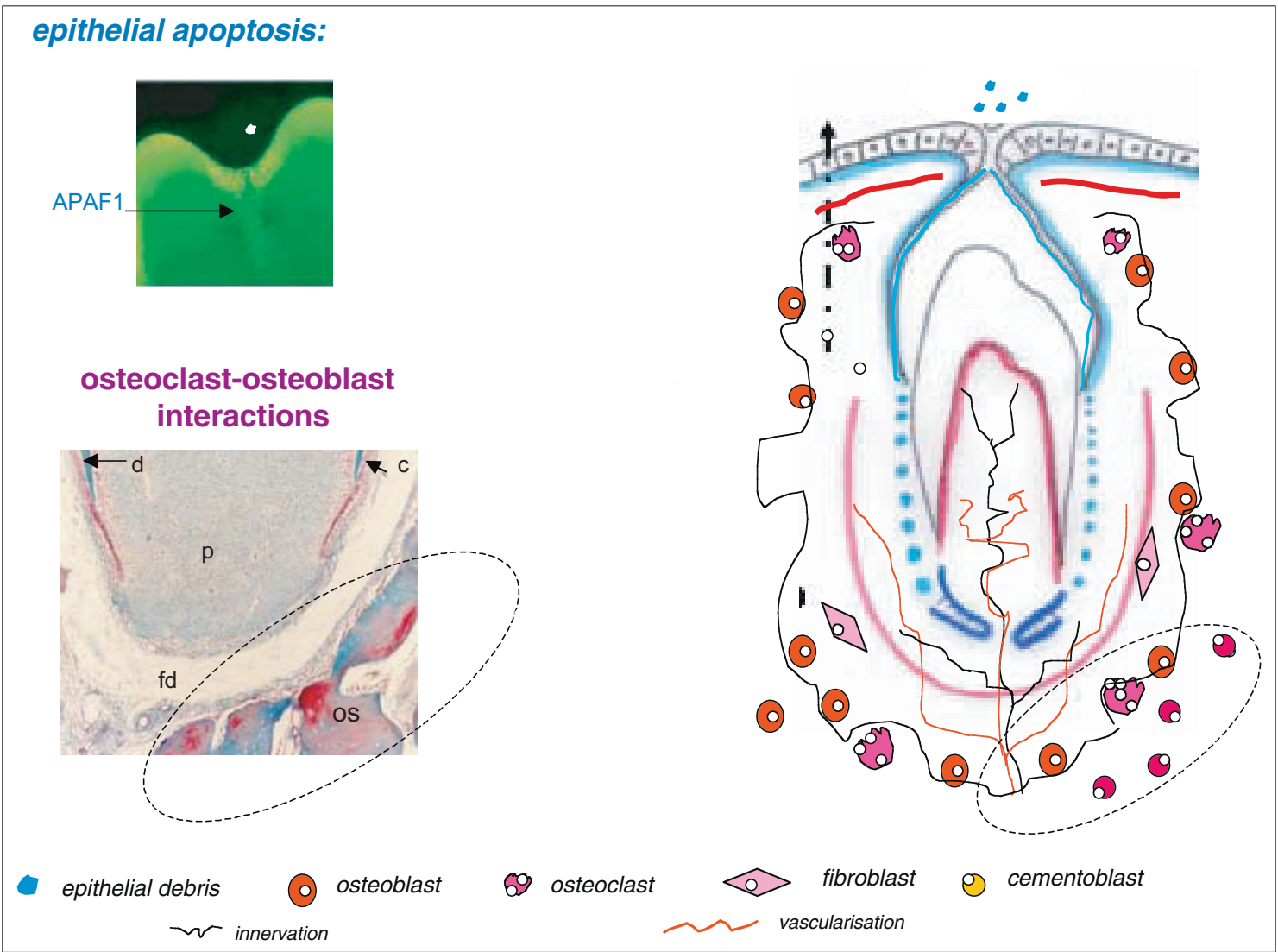

Figure 17

Root morphogenesis and eruption (mechanisms).

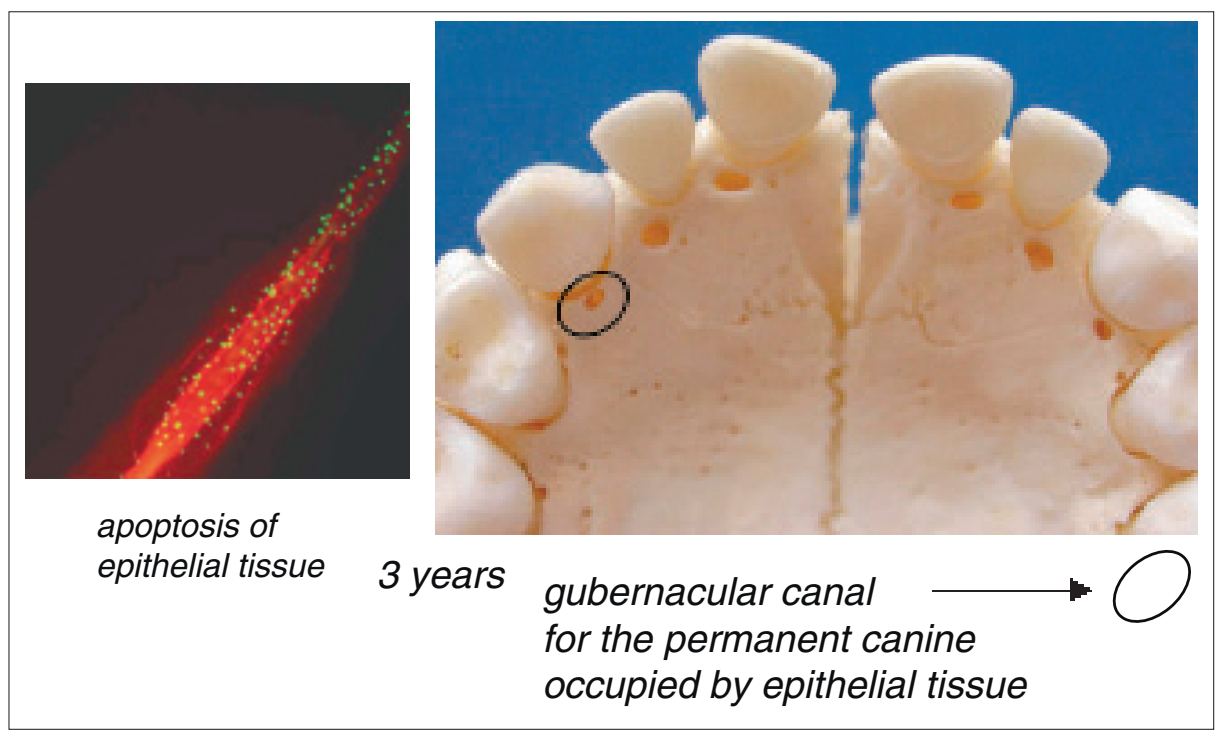

Figure 18 
temporary canine root tissues. Before the canine reaches the oral cavity, the gubernacular canal epithelium undergoes apoptosis, i.e. programmed cell death through the action of transcription factor APAF1 (fig. 19) ${ }^{19}$. The remains of the external epithelium, still connected to the crown, join the buccal epithelium to install the epithelial attachment.

During the post-natal phases, MSX2 takes over from MSX1 during allometric root growth and alveolar bone modelling. Expression of these
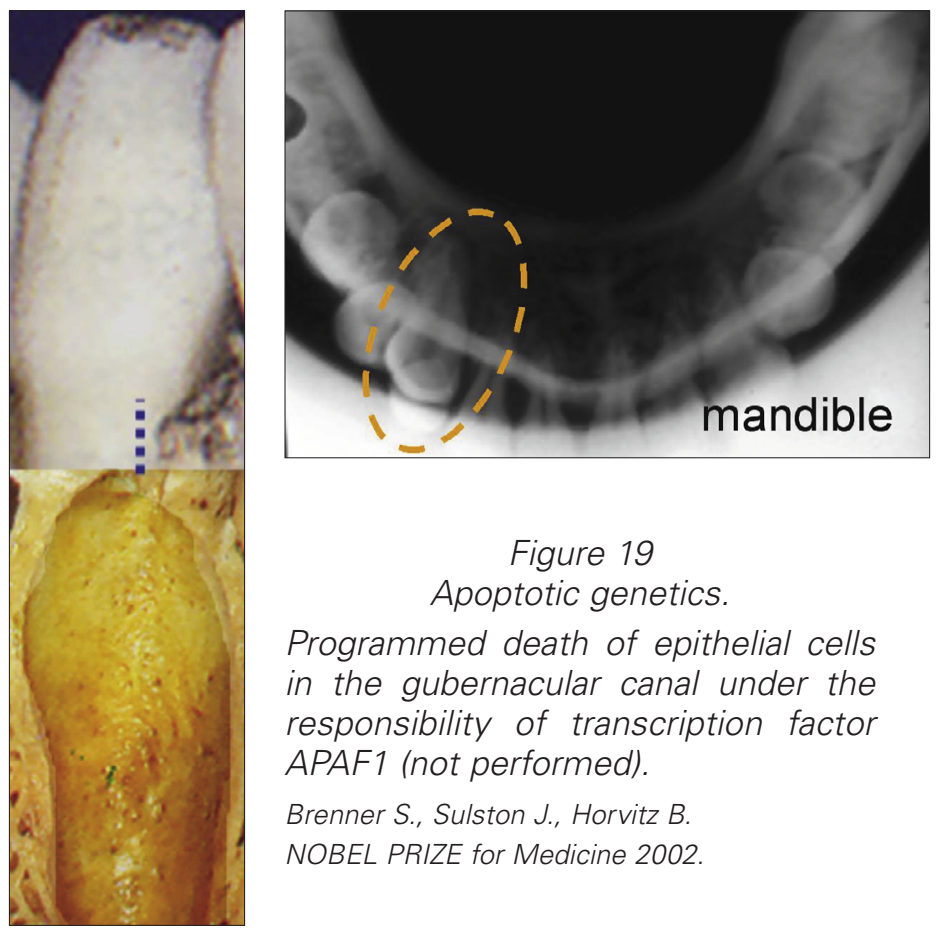

Figure 19

Apoptotic genetics.

Programmed death of epithelial cells in the gubernacular canal under the responsibility of transcription factor APAF1 (not performed).

Brenner S., Sulston J., Horvitz B.

NOBEL PRIZE for Medicine 2002.

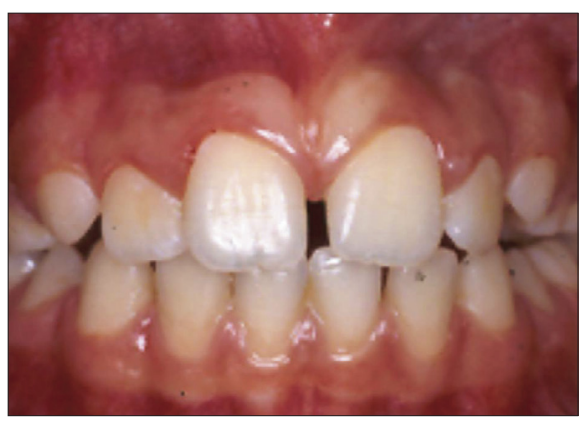

a

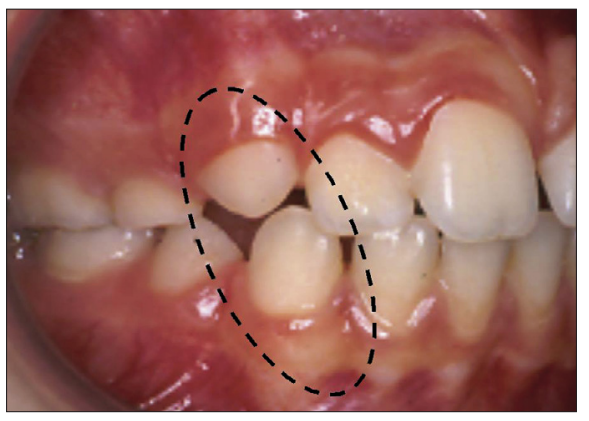

b

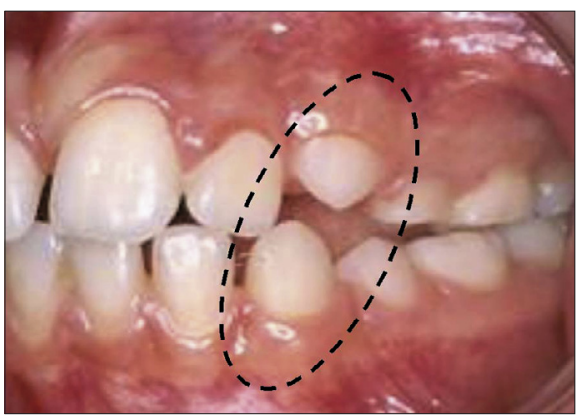

C

Figure 20

Eruption of permanent canines.

Gradual integration of the canines into the functional design set up by the first molars (Juliette, aged 10). 
two genes is triggered by growth factors: BMPs.

The canines will gradually come into the functional design already put into position by the first permanent molars (fig. 20 a to c).

NB:

- In the canine class only one temporary and one permanent tooth have to be controlled while the other classes are comprised of 2 temporary incisors and 2 permanent incisors, and 2 temporary molars and 5 permanent cheek teeth that have to be regulated per hemi-arch.

- The genetic mechanisms for constructing a tooth vary according to the type of tooth. The simpler the model of the tooth as with the uncomplicated canine, the fewer the variations will be as interactions proceed 29 .

- During a canine's crown morphogenesis, only a single primary centre, the enamel knot, has to operate $^{28}$

It may therefore be thought that stability in emplacement, formation and shape during crown morphogenesis concerns a single primary centre, the enamel knot 28 .

Accordingly, during the course of its crown and root morphogenesis, the canine benefits from much simpler application of genetic factors than do teeth developing in the other fields.

\section{5 - ANOMALIES IN SHAPE, MATURATION, ERUPTION OR FUNCTION}

Agenesis of permanent canines occurs only rarely and then usually in association with some disease entity. It is more frequent in the maxilla than in the mandible.

\section{5 - 1 - Isolated late eruption}

View of a 16 year old girl's overretained upper and lower left temporary canines. The usual age for these teeth being replaced by permanent

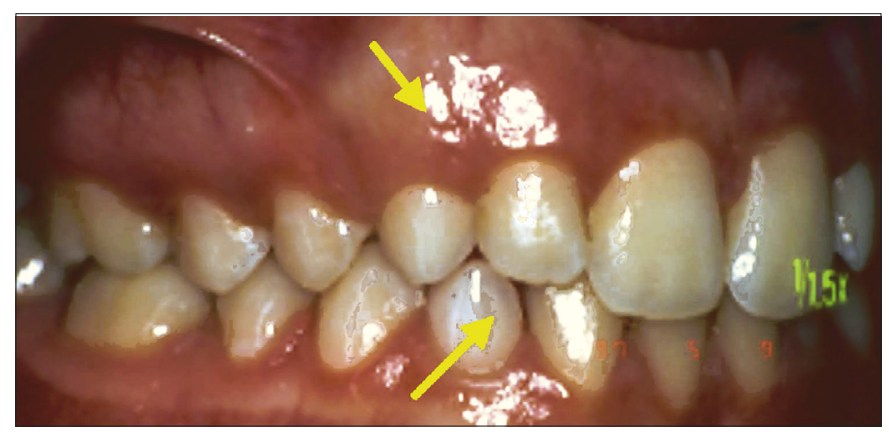

a

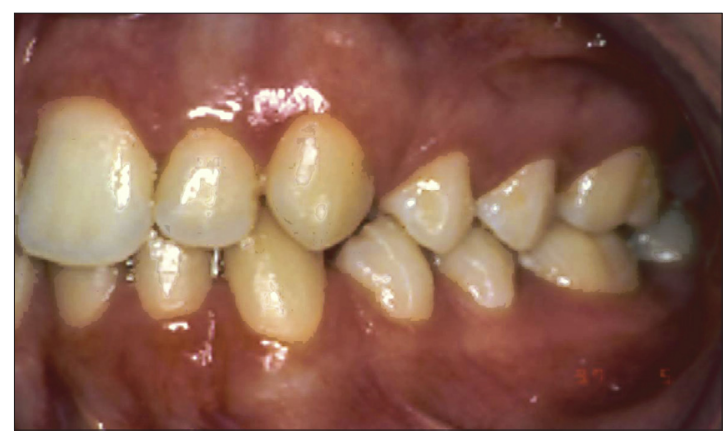

b

Figure $21 a$ and $b$

Isolated late eruption (Lucie M. aged 16).

52 and 83 on the arch. 
successors is $9-10$ years of age for the mandible and 11 to 12 for the maxilla. The roots of the two unerupted permanent canines have already formed. In the mandible, the interaction between the three elements constituting the dentoalveolar system (fig. 16, 17, 18, 19, $23 \mathrm{a}$ and b) has probably slowed down. In the maxilla, the same factors are also probably operating in addition to weak odontoclastic and osteoclastic activity driving the permanent canine along an eruption axis which is deviated palatally (fig. 24 a and b). After orthodontic treatment, the two permanent canines have assumed their proper positions in the dental arches (fig. 26 a and b, fig. 27 a to d).

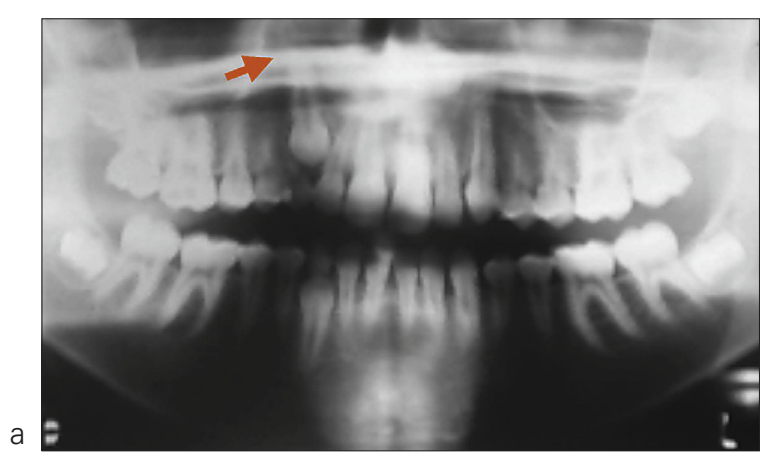

Fig. $22 a$ and $b$

Delayed eruption. Canines included 13, 43. (Lucie M.).

Apex constructed. Pulp still wide.

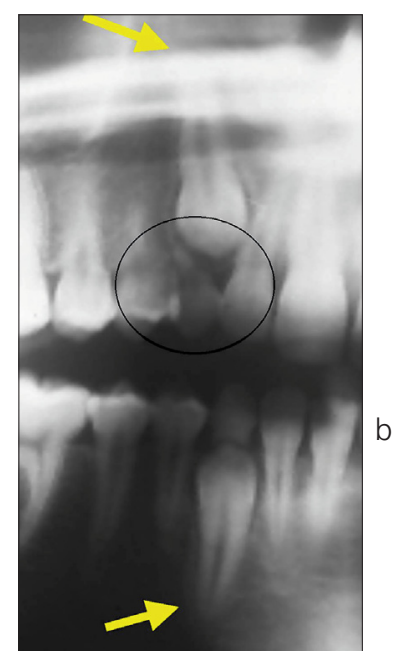

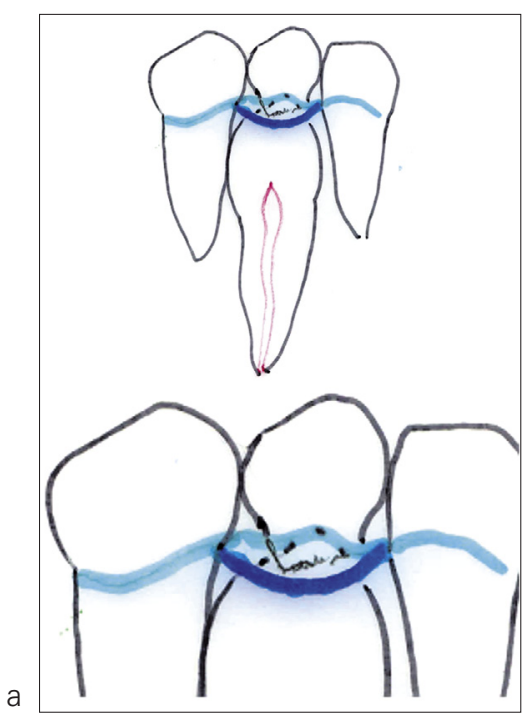

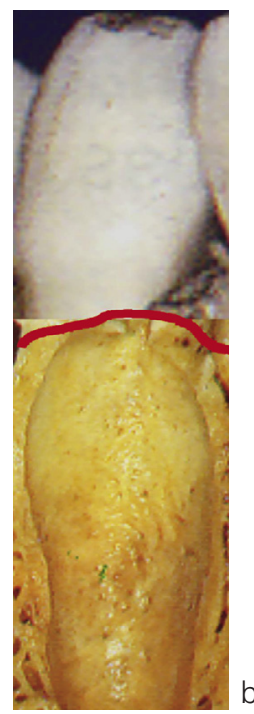

Figures $23 a$ and $b$

Connective obstacle. Apoptosis did not occur. Age: 16

Normal canine eruption at 9-10 years of age.
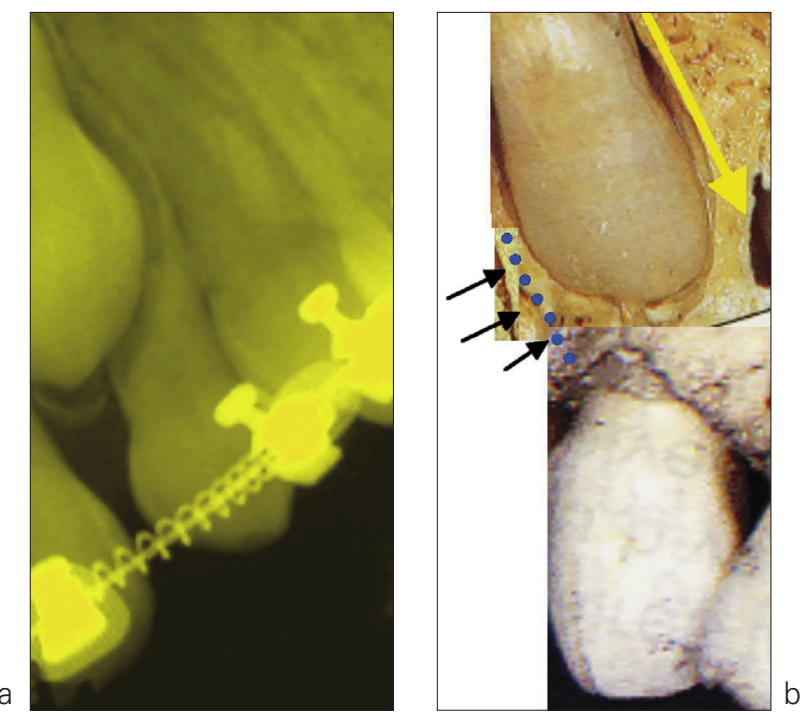

Figures $24 a$ and $b$

Normal canine eruption at 11-12 years of age and bone and root obstacles not resorbed by the odontoclasts (age: 16). 


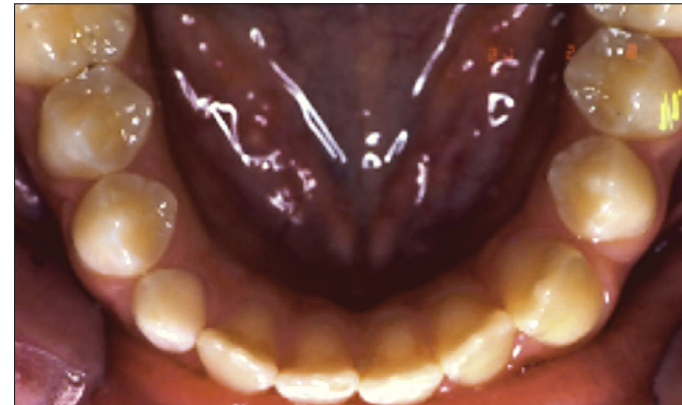

a

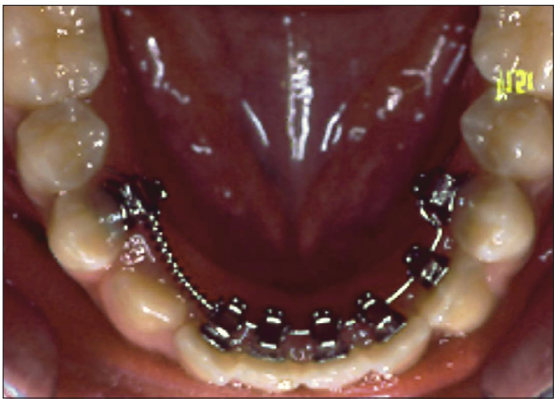

d

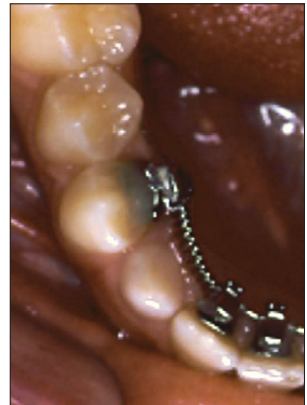

b

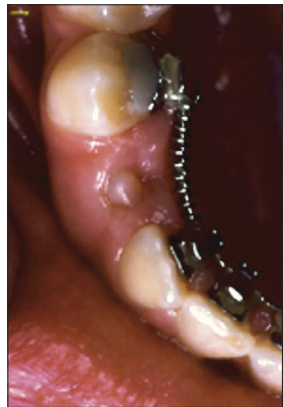

C

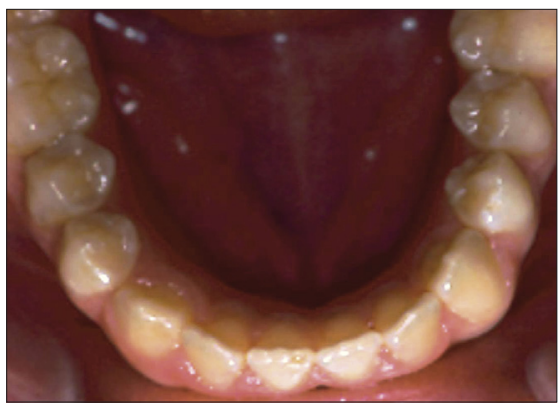

e

Figures 25 a to $e$

Orthodontic treatment in the mandible.

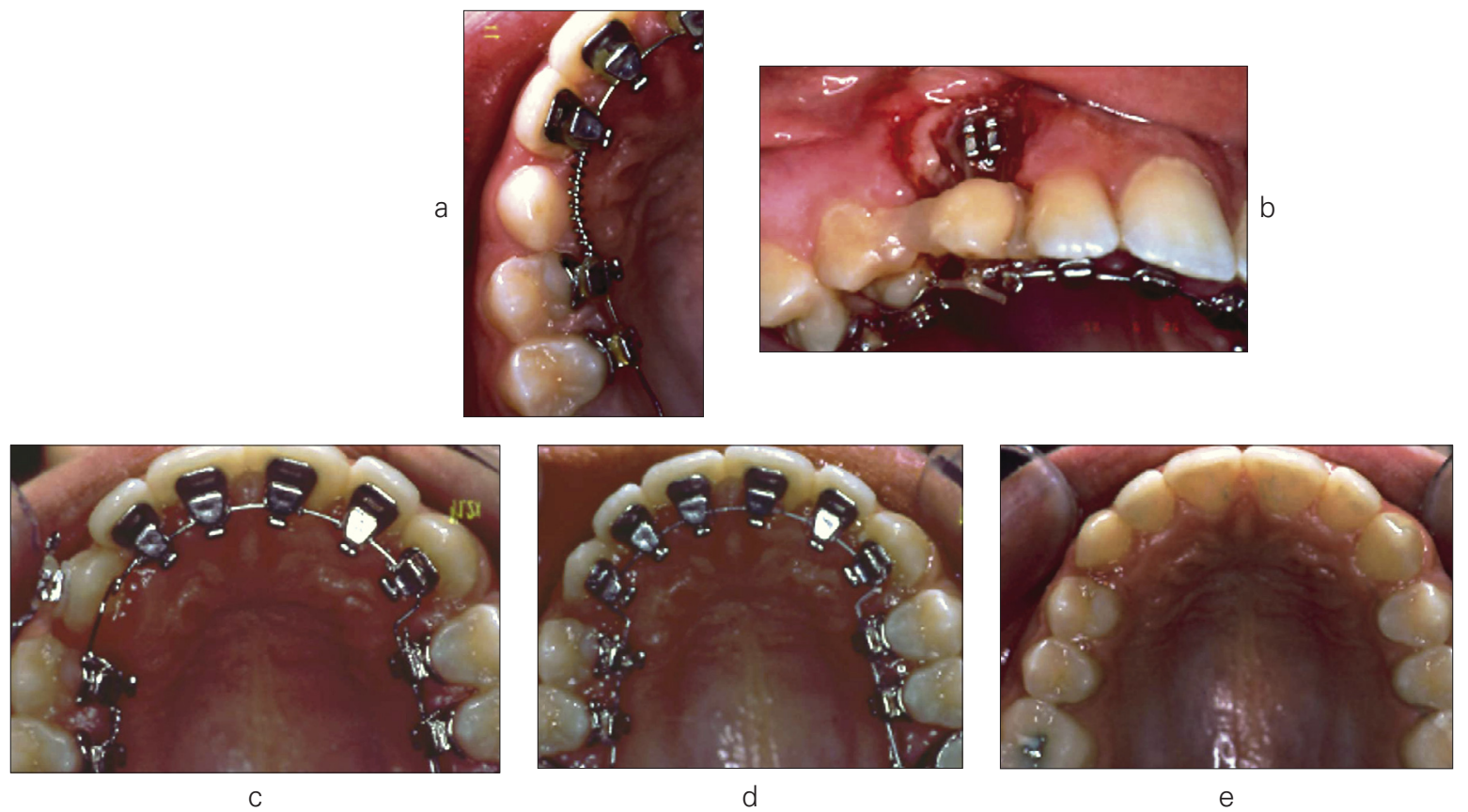

Figures 26 a to e

Orthodontic treatment in the maxilla. Creating space. Traction. (Lucie M.). 

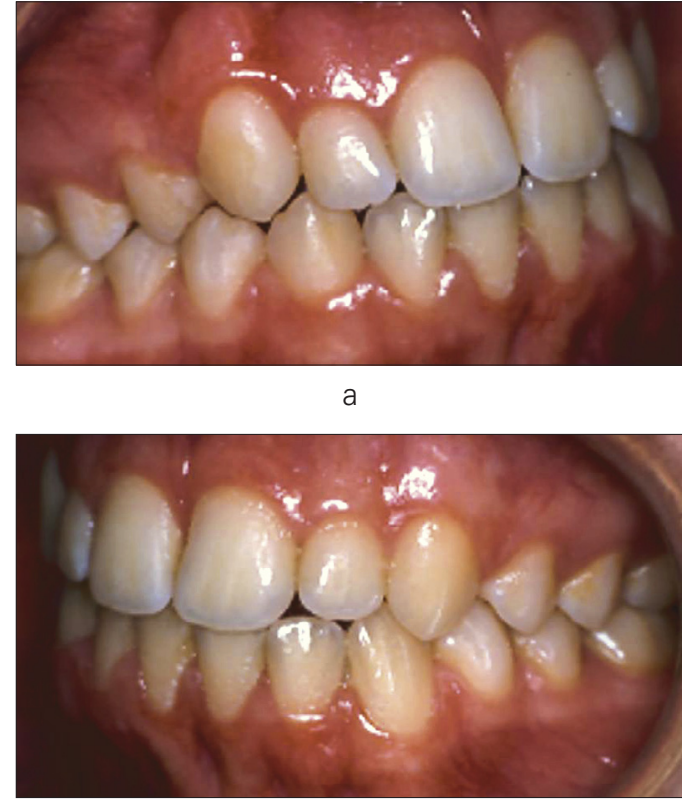

C

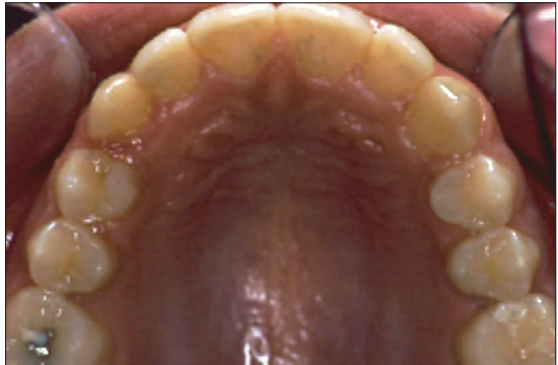

b

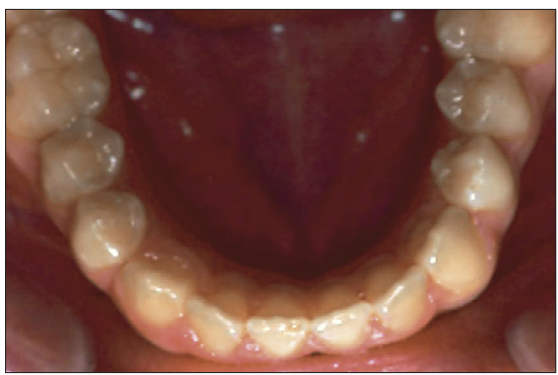

d

Figures 27 a to $d$

Integration of canines. Arches at the end of treatment.

5 - 2 - Anomalies of shape, eruption and function in syndromes

- Informative family for agenesis (fig. 28)
The MSX1 gene is responsible, in a family where agenesis, anomalies in shape, position, eruption and function of the canines was noted (fig. 29, 30, 31) 34 .

Molecular pathologies of the MSX1 transcription factor are responsible for

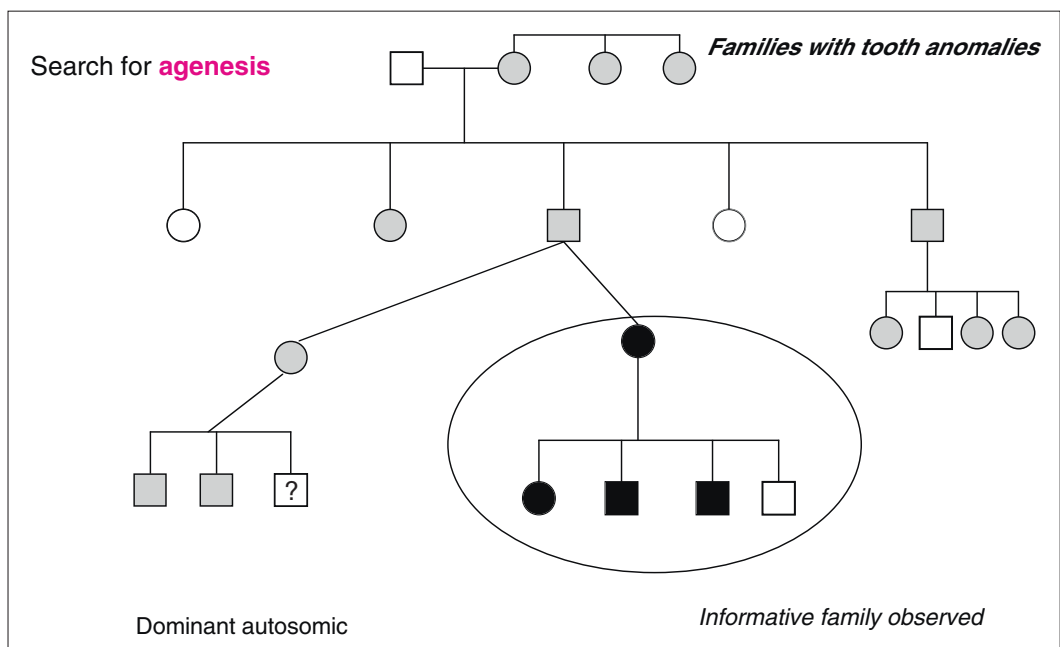

Figure 28

Search

for agenesis

in the family. 


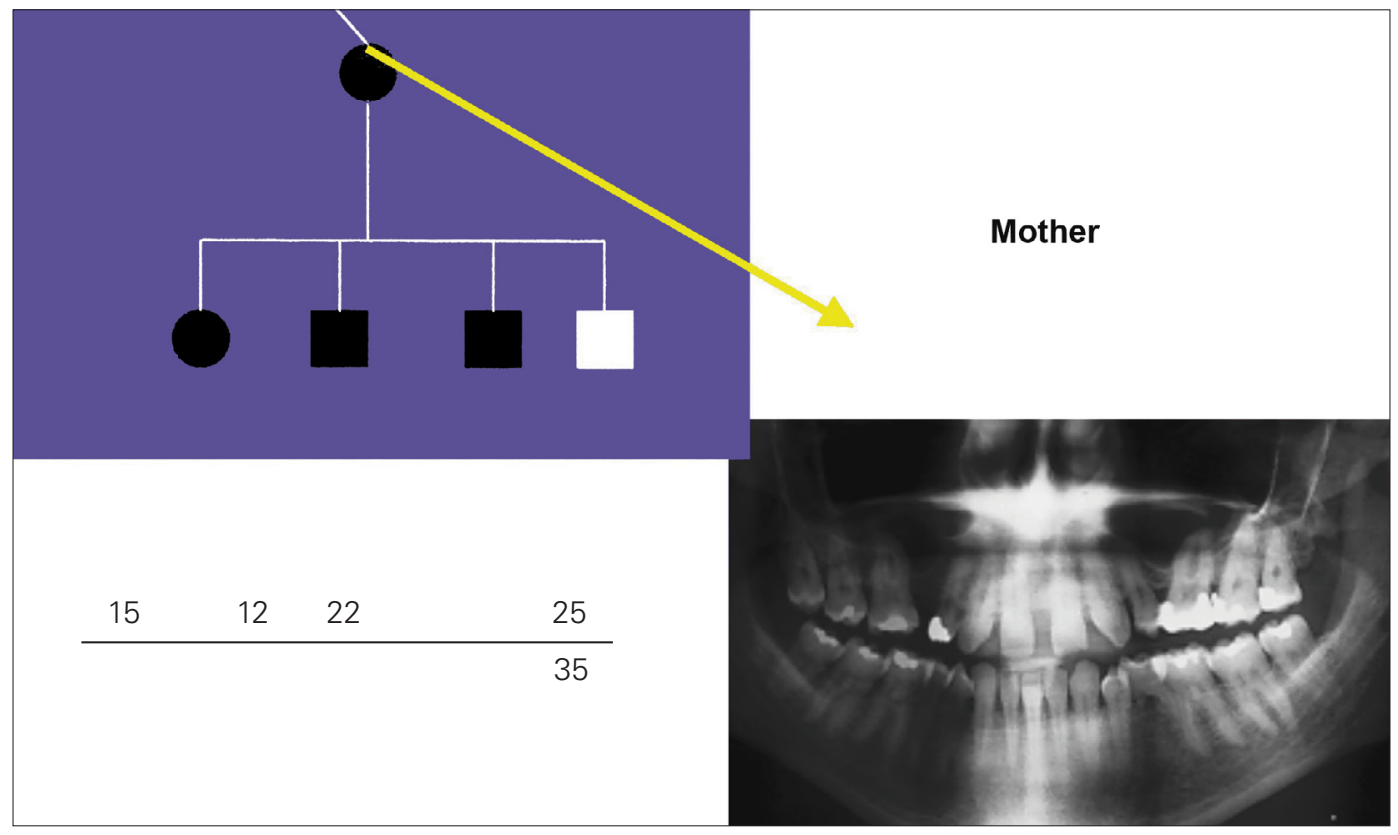

Figure 29

FTA Family.

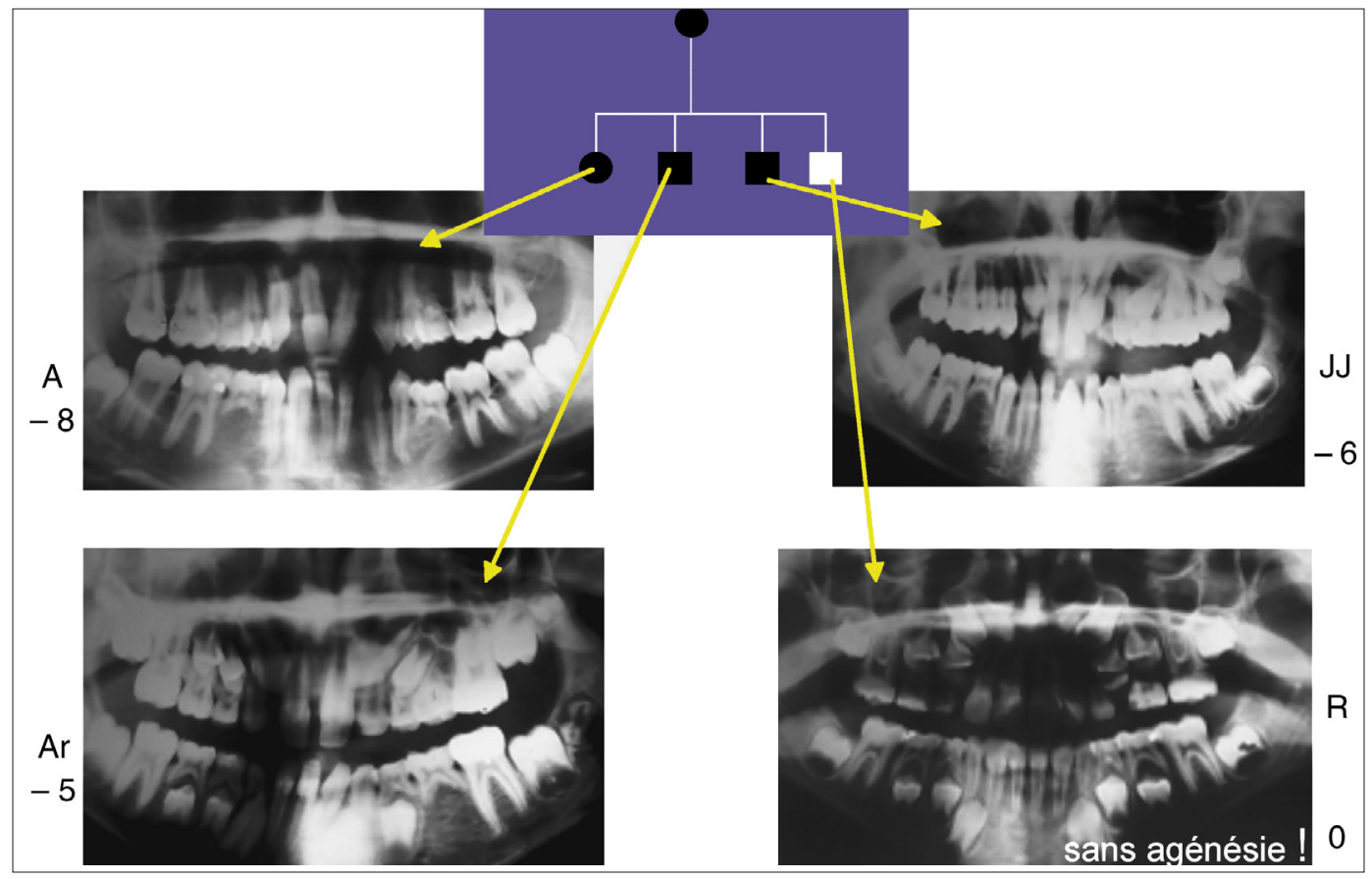

Figure 30

FTA Family: many anomalies.

All suffer from agenesis except the youngest child, but all have mesial positions and cross-bite occlusions. 
all the above-mentioned anomalies and the mesial position of the canine and molar classes as well as lateral crossbite occlusions (fig. 32).
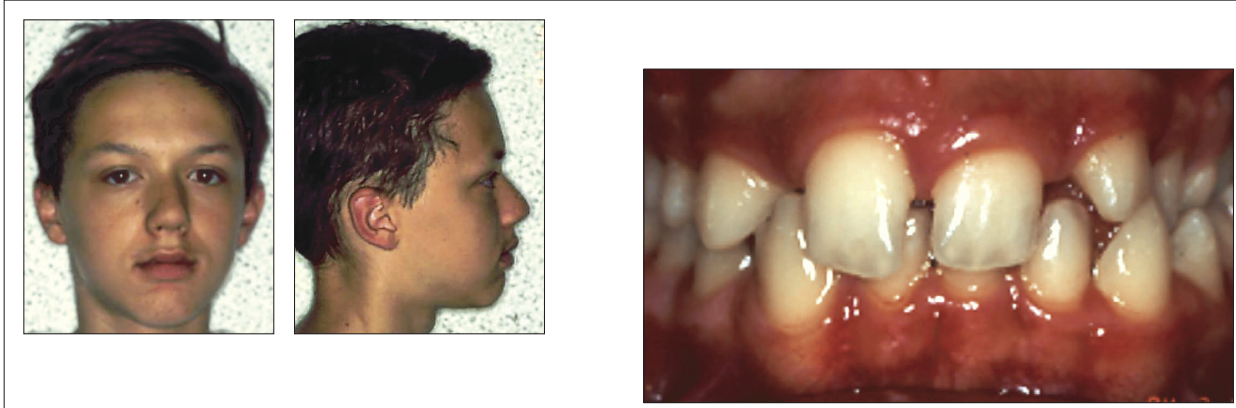

Agénésie \begin{tabular}{llll}
$15 \quad 12$ & 22 & 25 \\
\cline { 2 - 4 } & 31 & & 45
\end{tabular}
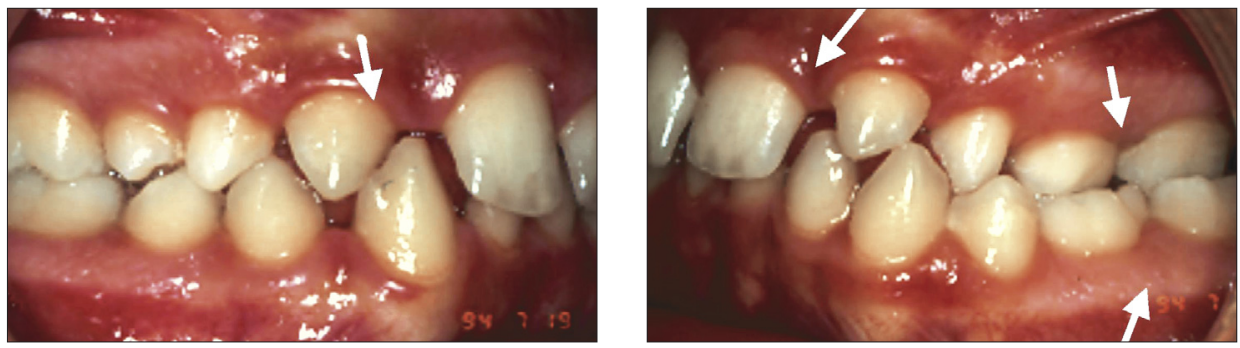

Figure 31

Arnaud, 13 years old. Anomalies in shape, position and function of the canine. Mesial positions and cross-bite occlusion.

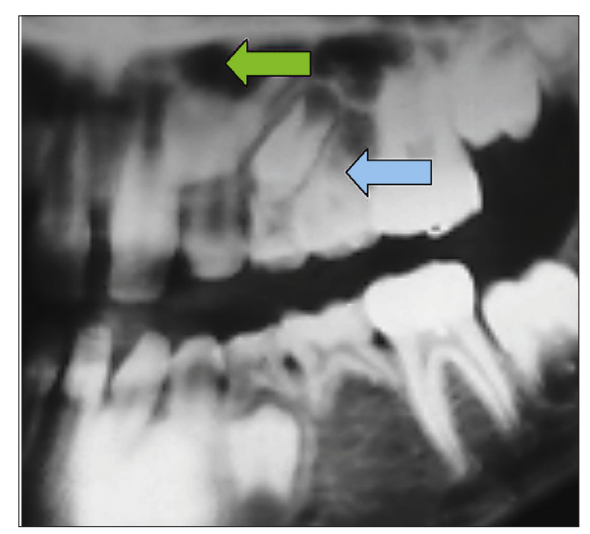

Arnaud

9 years of age

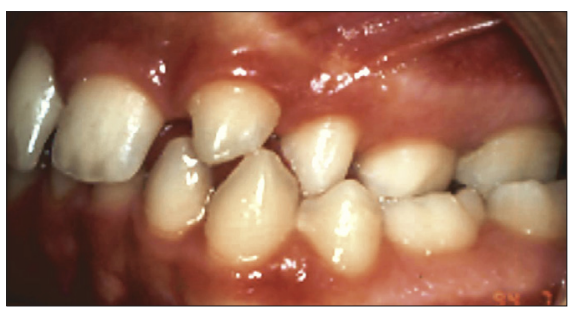

Cross-bite occlusion mesialisation of the canine class

close to the incisor class

and deviated eruption axis of the canine

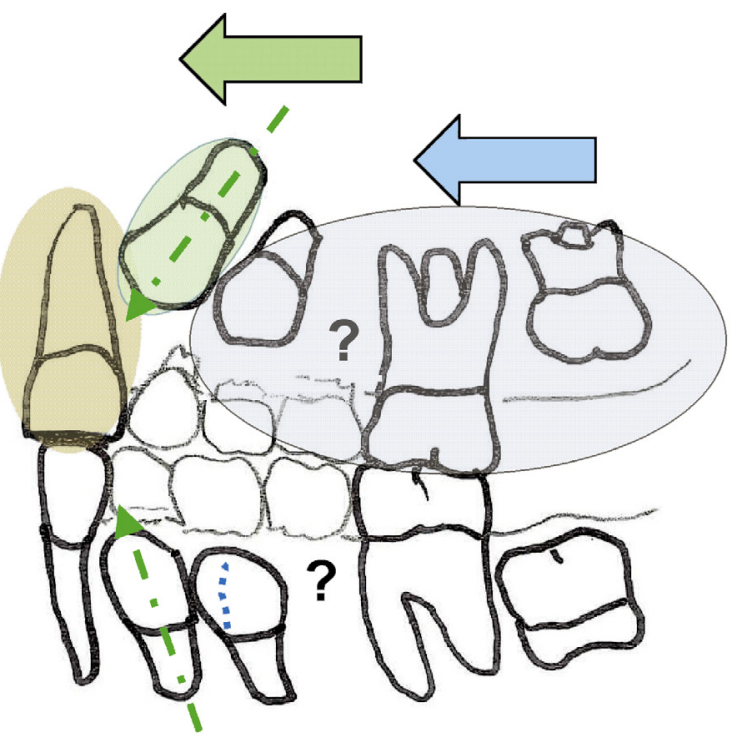

Figure 32

Genetic anomalies in the dentofacial system preventing normal integration of the canine in the functional dental design. 
- Cleidocranial dysostosis

Locus 6p21 on the short arm of chromosome 6 codes for a specific bone transcription factor CBFA1 (core binding factor A1). Mutation of this gene under MSX1 control leads to reduced osteoblast differentiation in the maxillary and alveolar bone. In this genetic pathology, phenotypic diversity is significant, from osteoporosis to cases of major dental anomalies (supernumerary teeth, maturation, eruption of canines and incorrect integration) (fig. 33 a to d, fig. $34 \mathrm{a}$ and b).
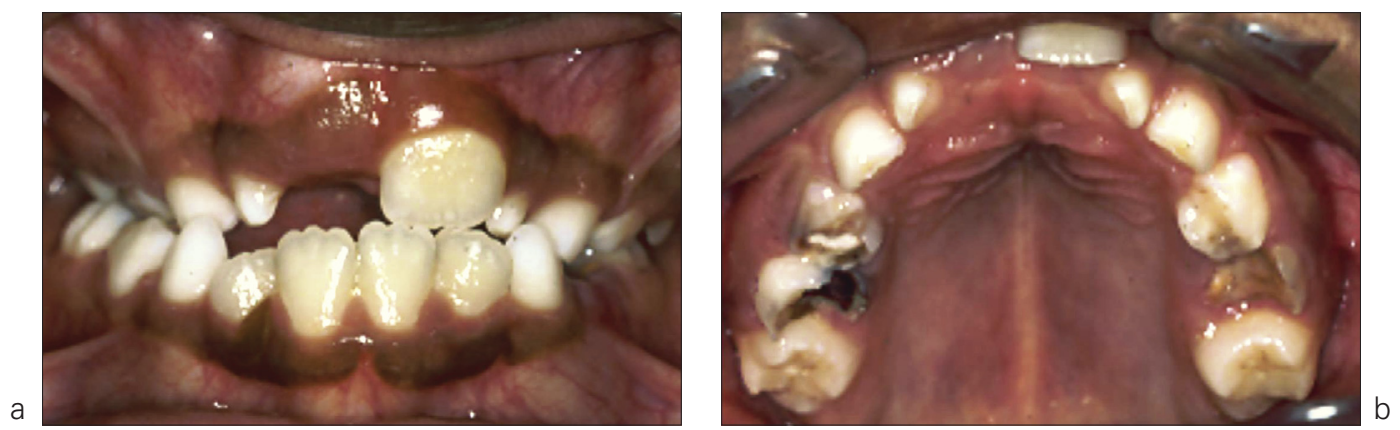

Suture non fermée
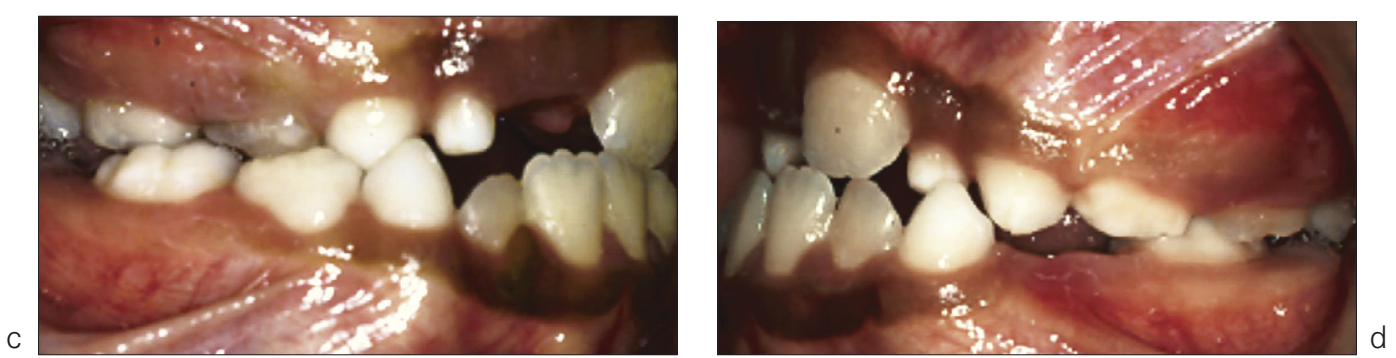

Figures 33 a to $d$

Cleidocranial dysostosis.

Shape anomalies. Late eruption and dental age. Faulty functional integration.
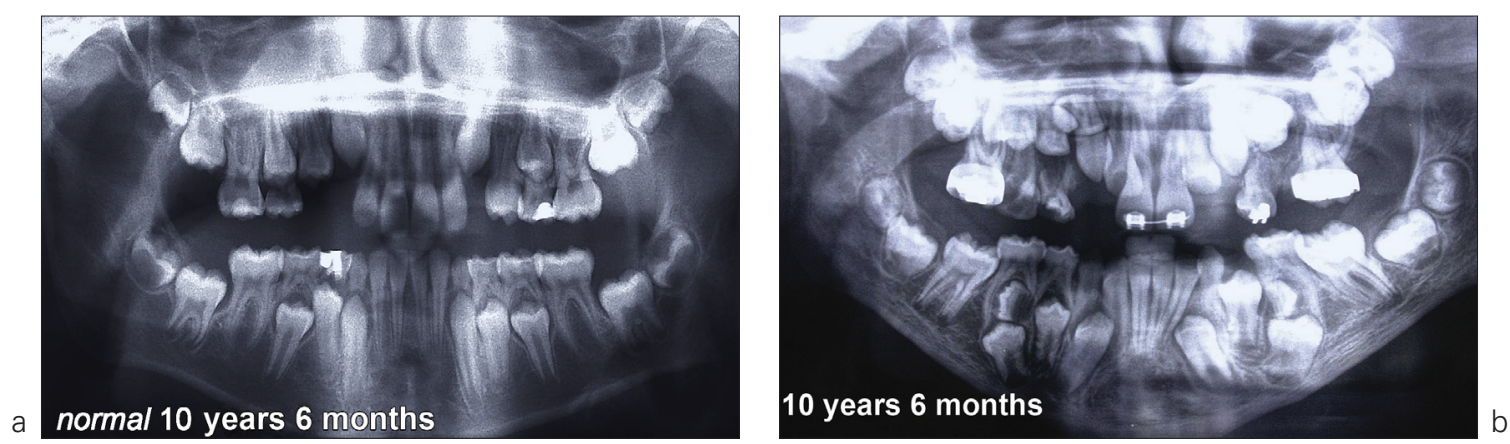

Figures 34 a and b

Cleidocranial dysostosis.

Anomalies of number and in dental maturation. 


\section{- Rieger's syndrome}

Two genes coding for transcription factors and two other loci, have been linked to this syndrome. One, the PITX2 (pituitary homeobox transcription factor 2) gene located at 4q25q26, codes for a transcription factor. This is involved in the SHH (sonic Hedgehog) signalling pathway in tooth morphogenesis, particularly that of the crown (fig. $35 \mathrm{a}$ and b). It also regulates BMP4 and FGF8 (growth factors which are important in dentoalveolar development).

\section{- Anhydrotic ectodermal dysplasia}

Responsibility is borne by gene Xq12-13.1. The mutated gene is TNF (tumour necrosis factor) and produces cuspid anomalies and ectodermal dysplasias (fig. 36 a and b).

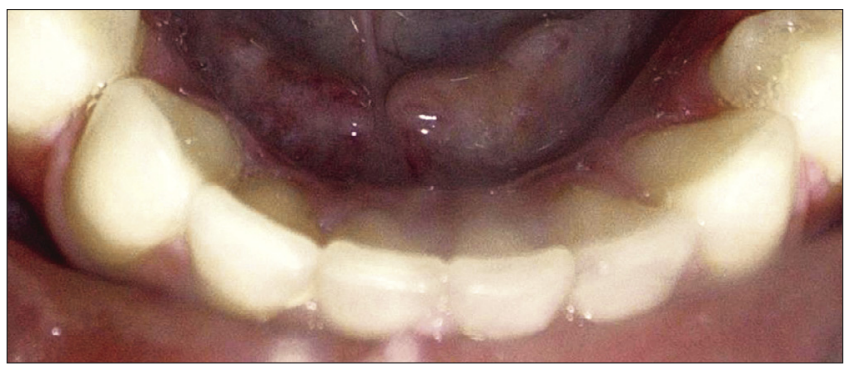

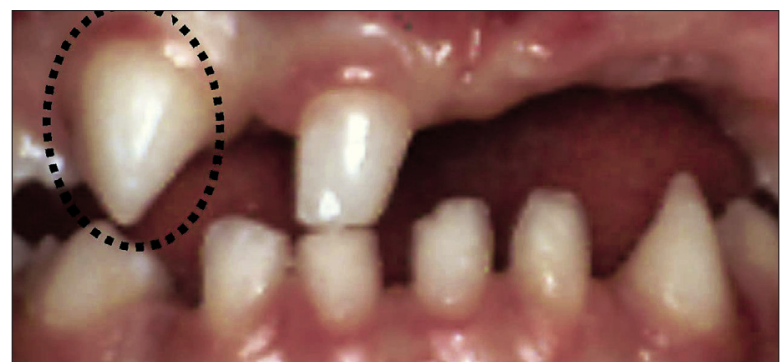

b

Figures 35 and $b$

a: normal morphology

Rieger's syndrome

b: oligodonty and abnormal conoid crown shape.
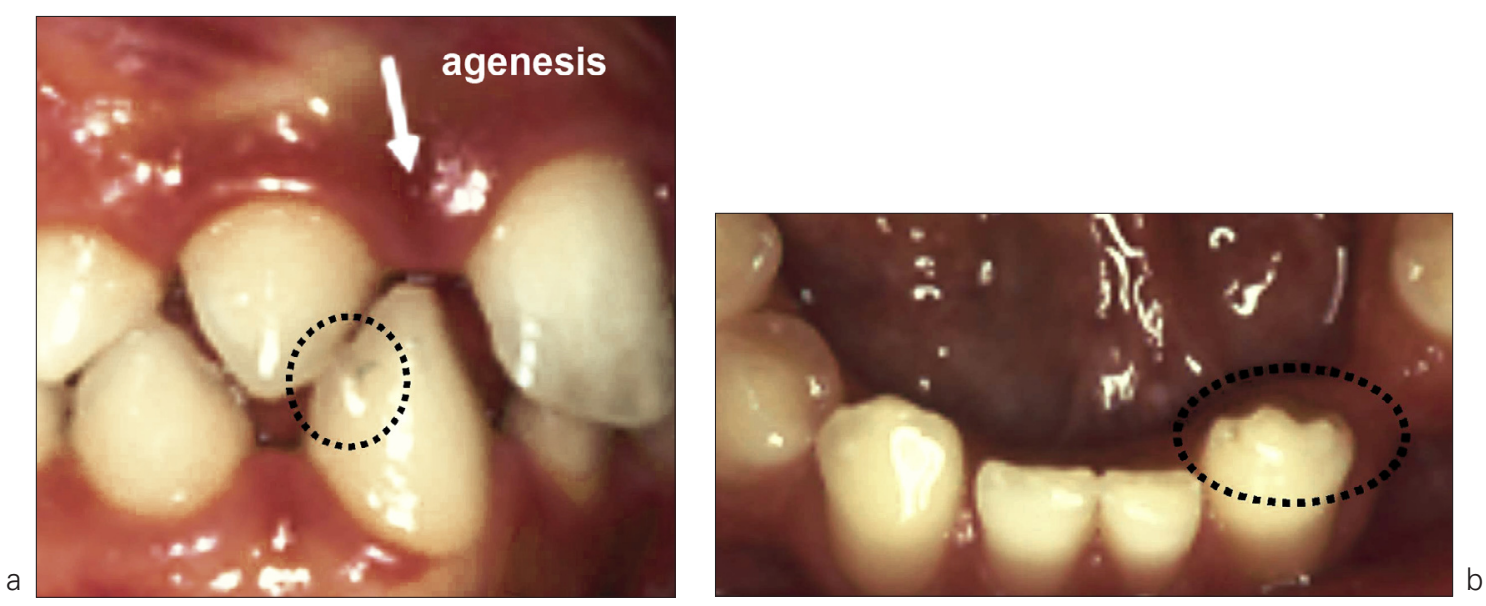

Figures 36 and $b$

Anhydrotic ectodermal dysplasia Xq12-q13.1

Agenesis of incisors and cuspid anomalies.

a: conoid shape and mini-cuspid;

b: cuspal anomalies of the canine. 


\section{- Environmental factors}

After chemotherapy, anomalies in number, shape, structure and eruption have been observed in children treated between the ages of 12 months and 5 years. The noxious effects of chemotherapy occur during the stages of crown and root morphogenesis in epithelial, pulpal and follicular tissues where mitotic activity is intense. Interactions between these tissues are diminished, causing a decrease in the size of crowns and roots (fig. 37 a and $b^{27}$.

Dioxin has also been reported as a cause of the same deleterious effects.
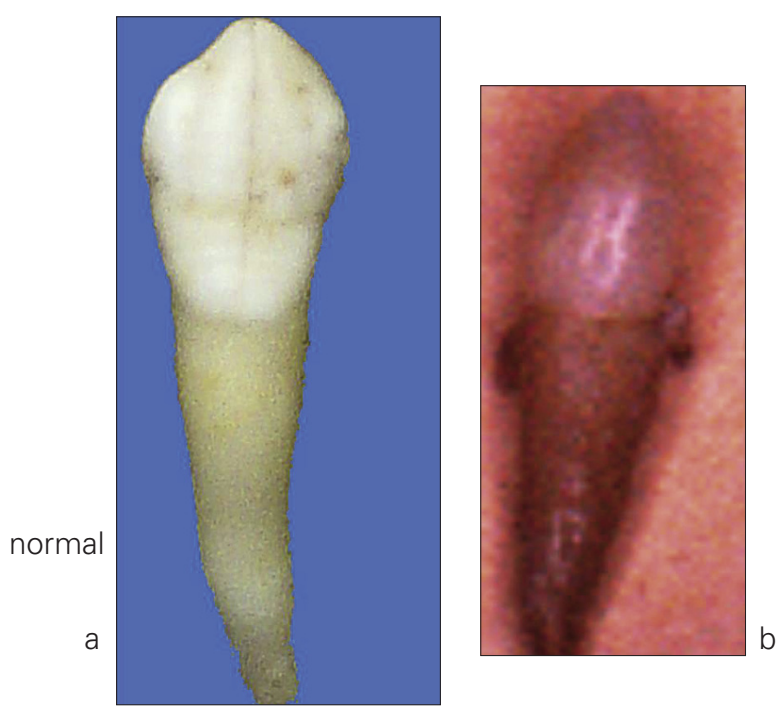

Figures $37 \mathrm{a}$ and $b$

Similar factors.

Dwarfism of crown and root.

g. Effects of chemotherapy on crown and root morphogenesis

(JM Salagnac).

\section{6 - MASTICATION AND CANINE FUNCTION}

During evolution, the canine guide in modern Man has become an exaptation phenomenon, that is. it was not selected to promote mastication but was co-opted to participate in it 25 .

During odontogenesis, at the age of 6 , pairs of molars implement the mastication design for each individual person. The other permanent teeth arrive in the arches during the fol- lowing years. Between the age of 9 and 12 , the canines are gradually integrated into the existing functional design.

In the permanent dentition, at the start of mastication, guidance is provided posteriorally by all the teeth in the molar class. On the working side, the canine then follows the mandible to the position of maximal intercuspation (fig. 38 a). 
"At the end of the masticatory cycle, it is the canine, contralateral to the mastication, which limits cycle amplitude and acts as the pivot of a second class lever to optimise elevator muscle action on the working side" (fig. 38 b) 20 .

In the sagittal plane, both the canines, with the four incisors, take part in shearing action (fig. $38 \mathrm{c}$ ).
Genetic interactions function as the chief governing force of the canine's morphogenesis, position in the jaw, and eruption (fig. 39 a). After its arrival in the buccal cavity, it becomes subject to environmental factors for its integration into the oral complex: functional dental schema (fig. 39 b), lingual, facial and masticatory muscle activity.

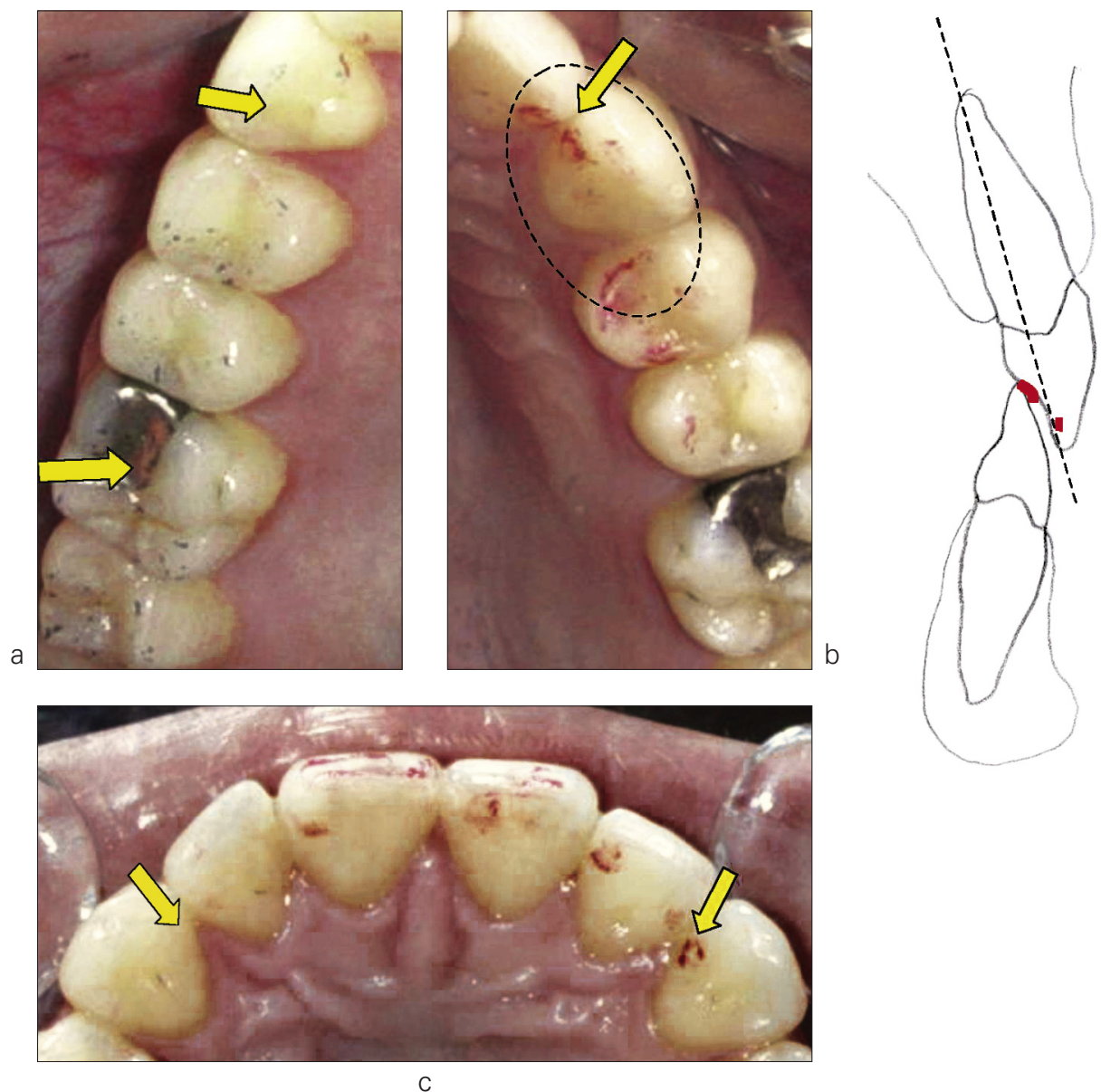

Figures 38 a to $c$

Mastication and canine function (Juliette 30 years old)

a: start of mastication

b: role of the canine and the premolars at the end of mastication

c: incision. 


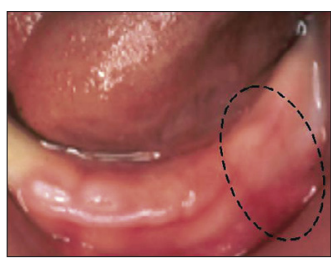

Juliette aged 6 months

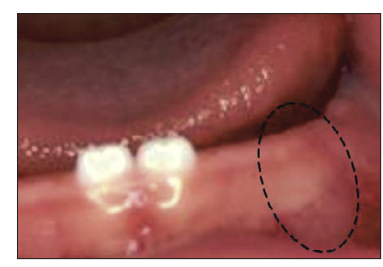

9 months

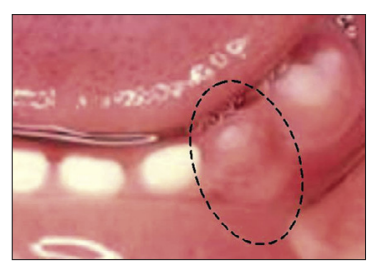

12 months

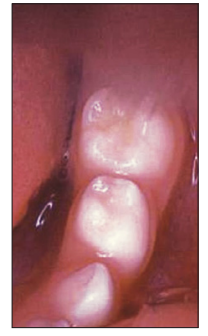

73 erupted before 63 3 years

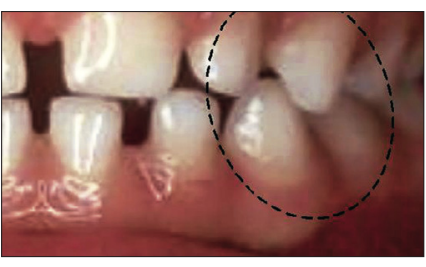

5 years

fig. 39 a

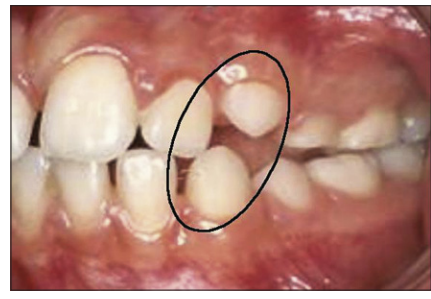

9 years

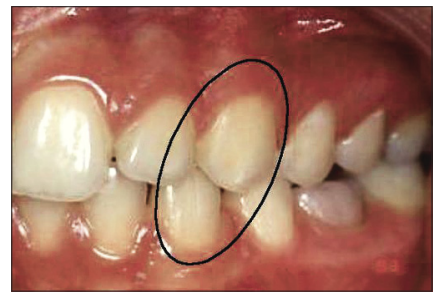

13 years

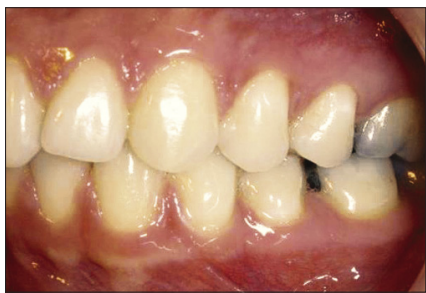

Juliette at 30 years old

33 before 23

fig. 39 b

Figures 39 a and $b$

Position and eruption sequences

a: genetically programmed;

$b$ : functional integration of canines.

\section{BIBLIOGRAPHY}

1. Baron R. I'ostéoclaste et les mécanismes moléculaires de la résorption osseuse. $M / S$ $2001 ; 17: 1260-9$.

2. Barreiro LB, Laval G, Quac H, Patin E, quintana-murci. - Natural selection has driven population differentiation in modern humans. Nature Genetics letters Published online: 3 February 2008.

3. Barsh G. Of ancient tales and hairless tails. Nature Genetics 1999;22:315-6.

4. Benoît R. Génétique et arcades dentaires. Orthod Fr 2004;75(2):107-21.

5. Berdal A et al. Differential impact of Msx1 and Msx2 Homeogenes on mouse maxillofacial skeleton Cells, tissues, organs. Vol 2009;189:1-4.

6. Berkovitz BKB. Oral anatomy histology and embryology, Elsevier 4e éd. 2009, 398 p.

7. Carels C. Concepts sur l'orthodontie du futur: spéculations ou illusions. Orthod Fr 2008;79(1):49-54.

8. Carvunis $A R$ et al. Biologie systèmique, des concepts d'hier aux découvertes de demain. M/S 2009;25:578-84.

9. Castenada B. Communication IFRO ADF 2008. 
10. Chapelle P, Granat J. Étude de 459 anomalies dentaires de nombre. Actualités Odonto Stomatol 1988;161:49-66.

11. Granat J, Heim JL. Nouvelle méthode d'estimation de l'âge dentaire des Néandertaliens. L' Anthropologie 2003;107:171-202.

12. Granat J, Peyre E. I'Homme, ses incisives, son évolution et l'anatomie cranio-faciale au xvie siecle. Biom Hum et Anthropol 2004;21(3-4):135-43.

13. Granat J, Genet-Varcin E, Heim JL. Évolution de la denture permanente des hominidés. Encycl Méd Chir Stomatologie et Odontologie 22003, S10 : 1992, 11 p.

14. Gomez-Brouchet A. Remodelage osseux: aspects biologiques et moléculaires. Service d'Anatomie et Cytologie Pathologiques, Toulouse : CHU Rangueil, 2009.

15. Headon DJ, Overbeek PA. Involvement of a novel Tnf receptor homologue in hair follicle induction. Letter nature genetics august 1999;22:370-74.

16. Jernvall J, Aaberg T, Kettunen P, Keränen S, Thesleff. The life history of an embryonic signalling center BMP4 induces P21 and is associated with apoptosis in the mouse tooth enamel knot. Dev 125;161-69.

17. Kere J et al. Nature Genet 1998;13:409-16.

18. Korbendau JM, Guyomard F. Chirurgie Parodontale Orthodontique. Ed CdP, 1998, $248 \mathrm{p}$.

19. Labouesse M. Mourir ou ne pas mourir, telle est la question et comment un minuscule petit ver y répondit. M/S 2002;18:1157-9.

20. Le Gall M, Lauret JF. La fonction occlusale. Implications cliniques. Ed CdP, 2008, 300 p.

21. Le monde Le génome humain porte les traces d'une sélection naturelle récente 13 février 2008.

22. Lesne A. Biologie des systèmes. L'organisation multiéchelle des systèmes vivants. M/S 2009;25:285-587.

23. Lezot et al. Epithelial Dlx2 homoegene expression and cementogenesis. J. of Histochemistry and Cytochemistry 2000;48:277-284.

24. Pickford M, Senut B. "Millenium Ancestor», a 6-million-year-old bipedal hominid from Kenya. S Afr J Sci 2001;97:22.

25. Picq P. In la fonction occlusale. Paris : EDP Sciences, 2008.

26. Pispa G, Thesleff I. Mechanisms of ectodermal organogenesis. Dev Biol 2003:195-205.

27. Salagnac JM, Benoît R. Incidence des thérapeutiques chimiothérapiques sur la dentition. Bulletin de I'ANCD, à paraître.

28. Salazard-Cuidad I, Jernvall J. A gene network model accounting for development and evolution of mammalian teeth. edit. D.B.Wake univ. California 2002:8116-8120.

29. Salazard-Cuidad I, Jernvall J. Graduality and Innovation in the evolution of complex phenotypes: insights from development. J experim Zool (Mol Dev Evol) 2005;304B: 619-31.

30. Senut B, Pickford M, Gommery D, Mein P, Cheboi K, Coppens Y. First hominid from the Miocene (Lukeino Formation, Kenya), C R Acad Sci Paris, Ser Ila 2001;332;137-44.

31. Sperber GH. Cranio-facial development, BC Decker 2001, 220 p.

32. Thomas BL, Sharpe PT. Patterning of the murine dentition by homeobox gene. Eur $\mathrm{J}$ Oral Sci Suppl 1998;1:48-54.

33. Tucker AS, Headon DJ, Courteney JM, Overbeck P, Sharpe PT. The activation level of the TNF family receptor, Edar, determines cusp number and tooth number during tooth development. Dev Biol 2004:185-94.

34. Vastardis $\mathrm{H}$. et al. A human MSX1 homeodomain missense mutation causes selective tooth agenesis. Nature genetics vol. 1996;13:417-42. 